Review

\title{
Atomic force microscopy: Determination of unbinding force, off rate and energy barrier for protein-ligand interaction
}

\author{
Chih-Kung Lee ${ }^{\text {a }}$, Yu-Ming Wang ${ }^{\text {a }}$, Long-Sun Huang ${ }^{\text {a }}$, Shiming Lin ${ }^{\text {a,b,* }}$ \\ a Institute of Applied Mechanics, National Taiwan University, Taipei, Taiwan \\ ${ }^{\mathrm{b}}$ Center for Optoelectronic Biomedicine, National Taiwan University, 1-1 Jen-Ai Road, Taipei 100, Taiwan
}

Received 6 December 2005; received in revised form 17 June 2006; accepted 19 June 2006

\begin{abstract}
Recently, atomic force microscopy (AFM) based force measurements have been applied biophysically and clinically to the field of molecular recognition as well as to the evaluation of dynamic parameters for various interactions between proteins and ligands in their native environment. The aim of this review is to describe the use of the AFM to measure the forces that control biological interaction, focusing especially on protein-ligand and protein-protein interaction modes. We first considered the measurements of specific and non-specific unbinding forces which together control protein-ligand interactions. As such, we will look at the theoretical background of AFM force measurement curves for evaluating the unbinding forces of protein-ligand complexes. Three AFM model dynamic parameters developed recently for use in protein-ligand interactions are reviewed: (i) unbinding forces, (ii) off rates, and (iii) binding energies. By reviewing the several techniques developed for measuring forces between biological structures and intermolecular forces in the literature, we show that use of an AFM for these applications provides an excellent tool in terms of spatial resolution and lateral resolution, especially for protein-protein and protein-ligand interactions.
\end{abstract}

(C) 2006 Elsevier Ltd. All rights reserved.

Keywords: Atomic force microscopy; Protein-ligand interaction; Protein-protein interaction; Unbinding force; Unbinding rate constant; Unbinding energy

\section{Contents}

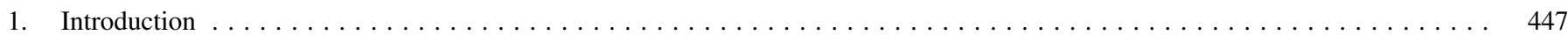

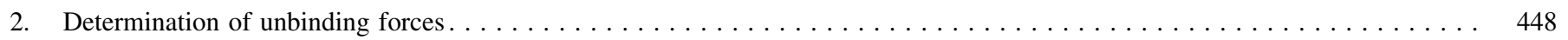

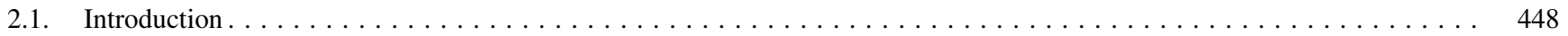

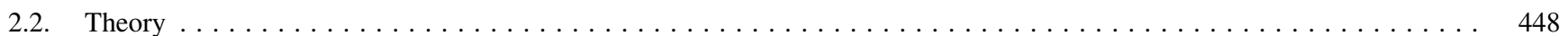

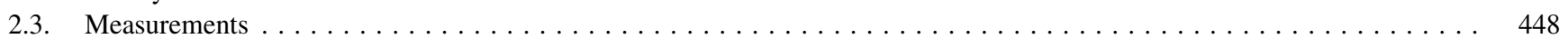

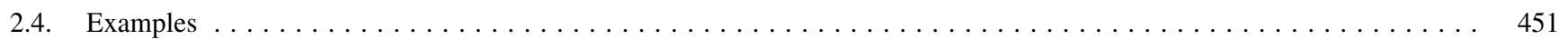

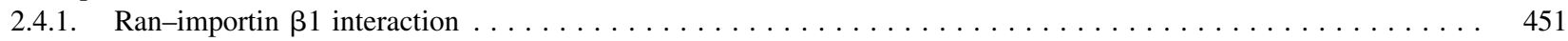

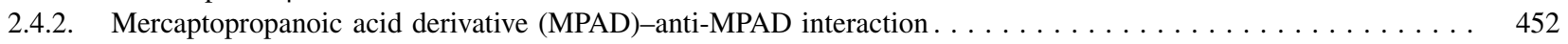

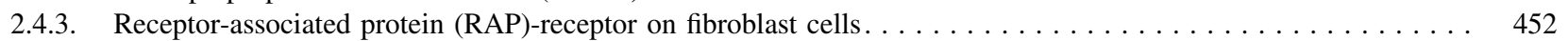

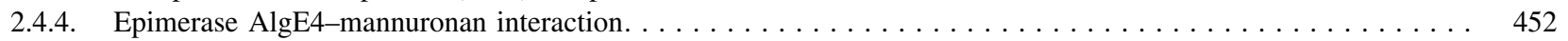

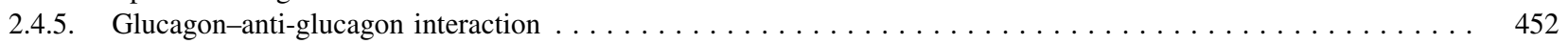

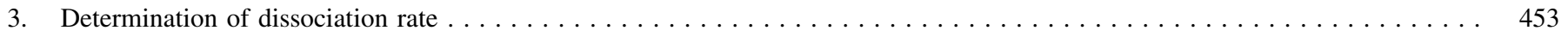

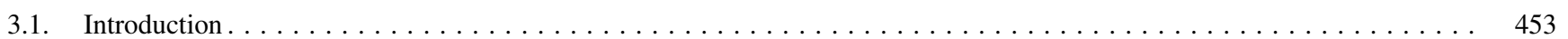

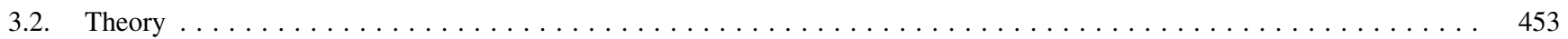

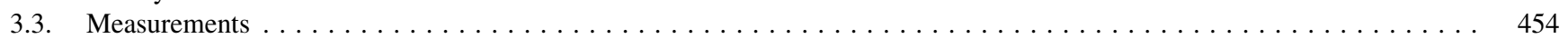

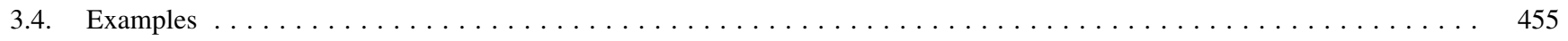

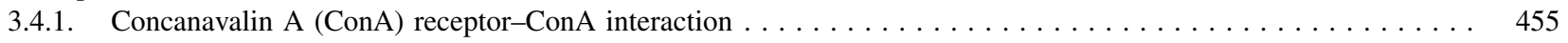

3.4.2. Ryanodine receptor $1(\mathrm{RYR} 1)$-anti-RYR1 interaction $\ldots \ldots \ldots \ldots \ldots \ldots$

\footnotetext{
* Corresponding author. Tel.: +886 22312 3456x8458; fax: +886 223949125.

E-mail address: sml@ntumc.org (S. Lin).
} 
3.4.3. Human $\alpha_{5} \beta_{1}$ integrins-GRGDSP dissociation $\ldots \ldots \ldots \ldots \ldots \ldots \ldots \ldots$

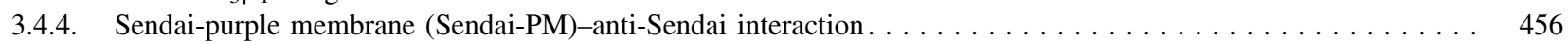

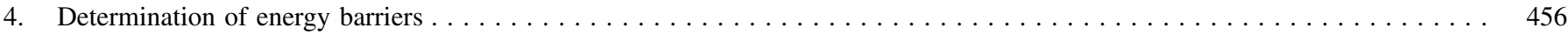

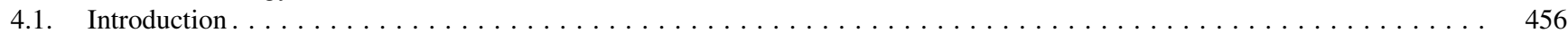

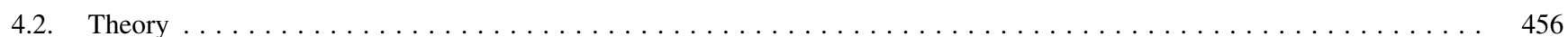

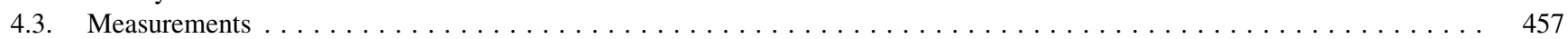

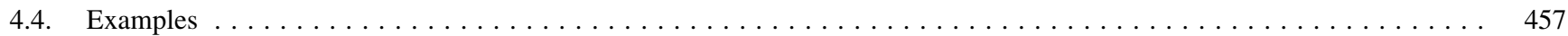

4.4.1. Human platelet $\alpha_{\mathrm{IIb}} \beta_{3}$ receptor-ligand (RGD) interaction $\ldots \ldots \ldots \ldots \ldots \ldots \ldots \ldots \ldots \ldots$

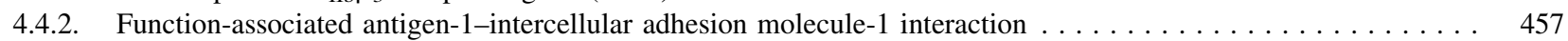

4.4.3. Granglioside $\mathrm{G}_{\mathrm{M} 1}$-cholera toxin B-oligomer $(\mathrm{ctB})$ interaction $\ldots \ldots \ldots \ldots \ldots$

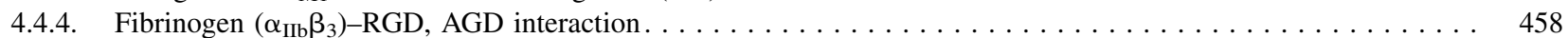

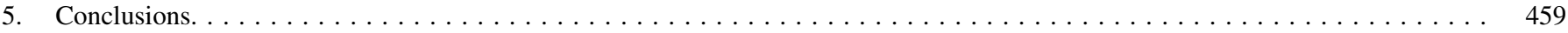

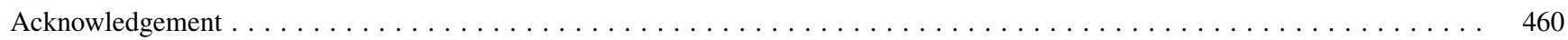

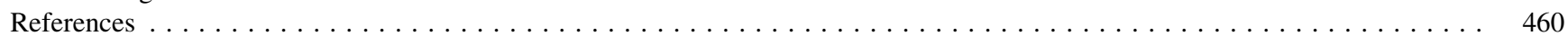

\section{Introduction}

Protein interaction with other proteins or ligands is controlled by a complex array of intermolecular forces. Although the intermolecular forces and binding energies which contribute to the stabilization of a protein-protein or proteinligand complex can be inferred indirectly from thermodynamic and kinetic approaches, or it can be determined by molecular calculations. Recent progress in atomic force microscopy (AFM) has made it possible to quantify directly the range and magnitude of the interaction forces between proteins and other molecules.

AFM is a nano-resolution technique which needs no prior complex preparation procedure for imaging the surface structure of insulating, semi-conductive or conductive samples (Binnig et al., 1986). The AFM has proven to be a suitable approach to study the structure of single bio-molecules (Hansma et al., 2003; Sitko et al., 2003; Chen et al., 2004; Kuznetsov et al., 2005), native bio-membranes (Schafer et al., 2002; Oberleithner et al., 2003; Li and Palmer, 2004; Reddy et al., 2004), as well as the measurement of molecular forces at the single-molecule level. Analysis of a sample under an AFM requires a scanning probe which is attached to a cantilever above the sample and then an accurate means for monitoring the vertical deflection of the lever. By using a very sharp probe on a flexible lever, the study of surface structure atomic resolution is possible (Chen et al., 1992). An AFM combines characteristics such as a high force sensitivity (theoretically $10^{-2} \mathrm{pN}$ ) (Lee et al., 1994), a high dynamic range (0.001$5000 \mathrm{nN}$ ) (Dammer et al., 1995), and a high positional accuracy $(0.01 \mathrm{~nm})$, with operational compatibility in a physiological environment. AFM has been successfully employed to measure intra-molecular unfolding forces of individual proteins (Fisher et al., 1999; Desmeules et al., 2002) and intermolecular forces between various ligands and receptor pairs (Chen and Moy, 2000; Lee and Marchant, 2001; Li et al., 2002; Bartels et al., 2003; Meadows et al., 2003; Kaur et al., 2004; Kienberger et al., 2005). Compared with other various biophysical approaches for direct measurements of intermolecular forces such as optical tweezers, magnetic torsion devices, and bio-membrane force probes (BFP), the AFM has the unique advantage of possessing high spatial resolution to detect molecular interaction at high lateral resolutions in combination with possessing an immense force sensitivity required under a physiological environmental condition.

For measurements associated with intermolecular proteinligand binding strengths, the ligand can be attached to the AFM tip and the protein attached to the substrate surface (or vice versa). The procedure requires bringing the AFM tip into contact with the surface so as to form a protein-ligand complex. When the AFM tip is retracted from the substrate surface, the force required for dissociation (i.e. the unbinding force), defined as the rupture force at the moment of sample separation, can be subsequently recorded and measured by pulling on the complex until the interaction bond breaks. Such experiments allow for estimation of unbinding forces, dissociation rate constants and bonding widths of the binding pockets (Lo et al., 2001; Kada et al., 2001; Lee and Marchant, 2001; Zhang et al., 2002; Cai et al., 2003; Lee and Marchant, 2003; Kokkoli et al., 2004; Kienberger et al., 2005). It can even provide the tool for mapping energy landscapes (Cai et al., 2003; Lee and Marchant, 2003). In addition, it can provide insight into the molecular dynamics of a protein/ligand recognition process by varying the loading rate of the force appliance (Lee and Marchant, 2003; Kokkoli et al., 2004; Kienberger et al., 2005).

The aim of this review is to describe the use of AFM for the determination of the forces and energies that control biological interaction dynamics, focusing especially on protein-protein and protein-ligand interaction modes. We will first consider measurements of the specific and non-specific unbinding forces which together control protein interactions. We will look at the theoretical background of AFM force measurement curves for evaluating unbinding forces of protein-ligand complexes. In addition, some of the most recent studies for determining the off rates and binding energies of protein-protein or protein-ligand interactions with AFM will be reviewed. By considering the several available techniques for measuring forces between biological structures, we can then see that the AFM is an excellent tool to use to measure protein-ligand and proteinprotein interactions as it can offer spatial as well as lateral resolution for most biological applications. 


\section{Determination of unbinding forces}

\subsection{Introduction}

Molecular unbinding forces between protein-specific ligands and surface-bound proteins have been recently measured by using AFM (see Table 1). The force required to separate a ligand from its specific binding site is different from the force needed to remove a non-specifically bound ligand (Pierce et al., 1994b). Since the AFM can measure the differences of the specific adhesion forces in a spatially resolved manner, the "specific adhesion force contrast" can be used to identify bound molecules and determine their distribution on the surface of the specimen. When the specificity of the protein interaction results in a force contrast, we can separate the topographical and chemical surface information. In biological systems, where molecular recognition events determine the specificity of interactions, the force contrast can be used to identify and map the distribution of those surface-immobilized proteins which are capable of binding AFM tip-bound ligands.

The unbinding force (i.e. rupture force) of protein-ligand interactions can be measured by employing the force-distance curve of the AFM. In a typical ligand rupture experiment the protein is bound to a substrate surface and the ligand bound to the AFM probe. The ligand-covered probe is then brought into contact with the substrate and binding takes place. The probe is then withdrawn from the surface, pulling the ligand out of its binding pocket. Then, the deflection of the lever, which is similar to a force exerted on the probe by the protein/proteinspecific ligand interaction, is recorded. The lever deflection is measured as it approaches and as it retracts from the substrate surface. The difference between these two traces occurs through adhesion between the probe and its surface and can be attributed to the protein/ligand interaction. The maximum adhesive force measured is thus known as the ligand unbinding force. In this article, we review AFM measurements of the unbinding force between surface-bound proteins and an AFM tip chemically modified with a protein-specific ligand.

\subsection{Theory}

When an AFM is used to measure the unbinding force between a protein and a protein-specific ligand, it is important to convert the plot of a deflection signal from a position sensitive photo-diode (PSPD) to a force unit. The cantilever deflection signal, measured in units of nanoamperes (nA) or voltage $(\mathrm{V})$, needs to be first converted to a deflection distance (nm), $d$, using the gradient (sensitivity, $\mathrm{nm} / \mathrm{A}$ or $\mathrm{nm} / \mathrm{V}$ ) of the linear portion of the retract trace in the contact region of the force curve (Allen et al., 1996). This deflection distance, $d$, is then converted into a force value (nanoNewton, $\mathrm{nN}$ ) acting on the AFM probe using the cantilever spring constant, $k$, and Hooke's law (Allen et al., 1997):

$F=k \times d$
The spring constant of a cantilever is determined from the individual frequency resonances with its shape factor which is expressed as

$k=2 w(\pi f L) \sqrt{\frac{\rho^{3}}{E}}$

where $L$ is the length of cantilever, $w$ the width of the cantilever, $\rho$ the density of the cantilever material, $E$ the elastic modulus (Young's modulus) of the cantilever material, and $f$ is the measured resonant frequency (Cleveland et al., 1993). In this force curve, the unbinding force (i.e. adhesion force) is characterized as the maximum force needed to begin separation of the two paired partners after contact. Therefore, protein-ligand (or proteinprotein) interaction between a tip coated with one half of a pair of the interacting species and a surface coated with the other half, can be identified by the increase in the magnitude of the force.

In most experimental set-ups, the average unbinding force as a function of the pulling speed is usually measured. With a series of generally accepted assumptions: (1) the rupture time is longer than diffusional relaxation time, (2) the acting force on the complex increases with a constant loading rate and (3) the binding process is on the quasi-equilibrium state (Evans and Ritchie, 1997, 1999), it can be shown that the most probable unbinding force is stated as

$F=\frac{k_{\mathrm{B}} T}{x} \ln \left(\frac{r x}{k_{\mathrm{off}}(0) k_{\mathrm{B}} T}\right)$

where $r$ is the loading rate, defined as the time derivative of the force applied to the bond. The loading rate $r$ is assumed to be equal to the product of the force constant of the AFM cantilever and its retraction speed. It is equal to the true loading rate $r$ only if the bond is fixed in position. This assumption has been used to analyze experimental AFM results for intermolecular proteinligand interactions (Paci et al., 2001).

\subsection{Measurements}

During a force measurement cycle (Fig. 1A), the piezoscanner moves toward the AFM tip by piezo expansion and velocity is kept constant until it is brought into contact with the tip (point B). As the forward motion continues, the cantilever is pressed into the sample surface until a point of maximum load is reached (point $\mathrm{C}$ ). The direction of motion is then reversed and the piezo-scanner is withdrawn from the AFM tip. During the retraction process for the force measurement, i.e., when the piezo-scanner withdraws from the tip surface, the tip adheres to the surface due to the interaction between the tip and the sample. In addition, a change in the slope of the curve (from points $\mathrm{C}-\mathrm{D}$ to $\mathrm{D}-\mathrm{E}$ ) will occur during the retraction process which can be attributed to a decrease in its effective spring constant. The strength of the unbinding force is then calculated from the difference between the maximum cantilever deflection (point E) during the retraction process of the curve and the point of zero cantilever deflection (point A).

However, we need to keep in mind that the interpretation of the unbinding force (i.e. adhesion force) may be complicated by 
Table 1

Protein-ligand unbinding force

\begin{tabular}{|c|c|c|c|c|c|}
\hline Molecular partners & Substrate & AFM tip & $\begin{array}{l}\text { Pulling } \\
\text { velocity } \\
(\mu \mathrm{m} / \mathrm{s})\end{array}$ & $\begin{array}{l}\text { Average } \\
\text { force }(\mathrm{pN})\end{array}$ & Reference \\
\hline \multicolumn{6}{|l|}{ Avidin/biotin system } \\
\hline Avidin/biotin & Biotin & Avidin & Not given & $160 \pm 20$ & Florin et al. (1994) \\
\hline Avidin/iminobiotin & Avidin & Iminobiotin & Not given & $85 \pm 10$ & Moy et al. (1994) \\
\hline Streptavidin/biotin & Streptavidin & Biotin & Not given & $257 \pm 25$ & \\
\hline Avidin/desthiobiotin & Avidin & Desthiobiotin & Not given & $94 \pm 10$ & Moy et al. (1994) \\
\hline Streptavidin/iminobiotin & Streptavidin & Iminobiotin & Not given & $135 \pm 15$ & \\
\hline Biotin/streptavidin & Streptavidin & Biotinylated BSA & Not given & $340 \pm 120$ & Lee et al. (1994a) \\
\hline Strepavidin/biotin & Strepavidin & Biotin & Not given & 300 & Allen et al. (1996) \\
\hline Biotin/streptavidin & Streptavidin & Biotin & Not given & $\sim 200$ & Wong et al. (1998) \\
\hline Avidin/biotin & Avidin & Biotin & 5 & $173 \pm 19$ & Lo et al. (1999) \\
\hline Strepavidin/biotin & Strepavidin & Biotin & 5 & $326 \pm 19$ & \\
\hline Streptavidin/biotin & Biotin & Streptavidin & $0.086-1$ & $126 \pm 2.3-207 \pm 5.8$ & Yuan et al. (2000) \\
\hline Strepavidin/biotin & Strepavdin & Biotin & $1-200$ & $167 \pm 20-442 \pm 17$ & Lo et al. (2001) \\
\hline Strepavidin/biotin & Strepavdin & Biotin & Not given & 454 & Stevens et al. (2002) \\
\hline \multicolumn{6}{|l|}{$\begin{array}{l}\text { Antigen/antibogy } \\
\qquad(\mathrm{Ag} / \mathrm{Ab}) \text { interaction }\end{array}$} \\
\hline Fluorescein/anti-fuorescyl Ab & Anti-fuorescyl Ab & Fluorescein & 0.182 & 200 & $\begin{array}{l}\text { Stuart and Hlady } \\
(1995)\end{array}$ \\
\hline $\begin{array}{l}\text { Human serum albumin } \\
\text { (HSA)/anti-HSA }\end{array}$ & HSA & Anti-HSA & 0.2 & $244 \pm 22$ & $\begin{array}{l}\text { Hinterdorfer et al. } \\
\text { (1996) }\end{array}$ \\
\hline Ferritin/anti-ferritin & Anti-ferritin (Ab) & Ferritin & Not given & $49 \pm 10$ & Allen et al. (1997) \\
\hline $\begin{array}{l}\text { Intercellular adhesion } \\
\text { molecule-1 } \\
\text { (ICAM-1)/anti-ICAM-1 Ab }\end{array}$ & ICAM-1 & Anti-ICAM-1 Ab & 4.68 & $100 \pm 50$ & $\begin{array}{l}\text { Willemsen et al. } \\
\text { (1998) }\end{array}$ \\
\hline $\begin{array}{r}\text { Ryanodine receptor } 1 \\
\text { (RYR1)/anti-RYR1 }\end{array}$ & $\begin{array}{l}\text { Ryanodine } \\
\text { receptor } 1 \text { (RYR1) }\end{array}$ & Anti-RYR1 & $0.066-0.3$ & $42-73$ & Kada et al. (2001) \\
\hline $\begin{array}{l}\text { Human chorionic } \\
\text { gonadotrophin } \\
\text { (hCG)/anti-hCG }\end{array}$ & $\mathrm{hCG}$ & Anti-hCG & Not given & 507 & Stevens et al. (2002) \\
\hline $\begin{array}{c}\text { Mercaptopropanoic acid } \\
\text { derivative of atrazine } \\
\text { (MPAD)/anti-MPAD }\end{array}$ & & Anti-MPAD & Not given & $511.7 \pm 244.1$ & Kaur et al. (2004) \\
\hline $\begin{array}{l}\text { Sendai-purple membrane } \\
\text { (Sendai-PM)/anti-Sendai } \\
\text { antibody }\end{array}$ & Sendai-PM & Anti-Sendai & $0.2-5$ & $70-170$ & $\begin{array}{l}\text { Kienberger et al. } \\
(2005)\end{array}$ \\
\hline \multicolumn{6}{|l|}{ Other protein/protein interaction } \\
\hline Cell adhesion proteoglycans & Proteoglycans & Proteoglycans & Not given & 125 & Dammer et al. (1995) \\
\hline Muscle proteins actin/myosin & $\begin{array}{l}\text { Ultraavidin-coated } \\
\text { fluorescent acrylamide } \\
\text { nanobead with } \\
\text { biotinylated myosin }\end{array}$ & Biotin & 0.0334 & $\begin{array}{l}14.8 \pm 4 \text { and } \\
24.7 \pm 1.4\end{array}$ & Nakajima et al. (1997) \\
\hline $\begin{array}{l}\text { Recombinant } \\
\text { P-selectin/P-selectin } \\
\text { glycoprotein ligand-1 } \\
\text { (PSGL-1) }\end{array}$ & P-selectin & PSGL-1 & 2.8 & $\sim 165$ & Fritz et al. (1998) \\
\hline $\begin{array}{l}\text { Ab single-chain } \mathrm{Fv}(\mathrm{scFv}) \\
\text { fragment/fluorescein }\end{array}$ & $\begin{array}{l}\text { Ab single-chain } \mathrm{Fv} \\
\text { fragment }(\mathrm{scFv}) \\
\text { with C-terminal } \\
\text { Cys residue }\end{array}$ & Fluorescein & 1 & $50 \pm 4$ & Ros et al. (1998) \\
\hline $\begin{array}{l}\text { Citrate synthase/E. coli } \\
\text { chaperonin GroEL }\end{array}$ & GroEL & Citrate synthase & Not given & $420 \pm 100$ & Vickier et al. (1998) \\
\hline $\begin{array}{l}\beta \text {-Lactamase/E. coli } \\
\text { chaperonin GroEL }\end{array}$ & GroEL & $\beta$-Lactamase & Not given & $240 \pm 70$ & \\
\hline Insulin/insulin & Insulin & Insulin & Not given & 1300 & Yip et al. (1998) \\
\hline $\begin{array}{l}\text { Myelin basic protein/lipid } \\
\text { bilayers }\end{array}$ & Lipid bilayers & Myelin & 1 & $140 \pm 60$ & Mueller et al. (1999) \\
\hline Osteopontin $/ \alpha_{\mathrm{v}} \beta_{3}$ integrin & $\alpha_{\mathrm{v}} \beta_{3}$ Integrin & Osteopontin & $1-50$ & 50 & $\begin{array}{l}\text { Lehenkari and Horton } \\
\text { (1999) }\end{array}$ \\
\hline $\begin{array}{l}\text { Vascular endothelial } \\
\text { (VE)-cadherins-Fc }\end{array}$ & VE-cadherins-Fc & VE-cadherins-Fc & $0.2-4$ & $15 \sim 150$ & $\begin{array}{l}\text { Baumgartner et al. } \\
(2000)\end{array}$ \\
\hline
\end{tabular}


Table 1 (Continued)

\begin{tabular}{|c|c|c|c|c|c|}
\hline Molecular partners & Substrate & AFM tip & $\begin{array}{l}\text { Pulling } \\
\text { velocity } \\
(\mu \mathrm{m} / \mathrm{s})\end{array}$ & $\begin{array}{l}\text { Average } \\
\text { force }(\mathrm{pN})\end{array}$ & Reference \\
\hline $\begin{array}{l}\text { Concanavalin } \mathrm{A}(\mathrm{Con} \mathrm{A}) \\
\text { receptor/ConA }\end{array}$ & $\begin{array}{l}\text { ConA receptors on } \\
\text { the surface of NIH3T3 } \\
\text { fibroblast cells }\end{array}$ & ConA & Not given & $86 \pm 2.6$ & Chen and Moy (2000) \\
\hline Lactose/bovine heart (BHL) & BHL & Lactose & 1.2 & $34 \pm 6$ & Dettmann et al. (2000) \\
\hline $\begin{array}{l}\text { Lactose/lactose-binding } \\
\text { immunoglobulin G (IgG) }\end{array}$ & Lactose & $\operatorname{IgG}$ & 1.2 & $36 \pm 4$ & \\
\hline Lactose/Viscum album (VAA) & VAA & Lactose & 1.2 & $47 \pm 7$ & \\
\hline Lactose/Ricinus communis (RCA) & Lactose & $\mathrm{RCA}$ & 1.2 & $58 \pm 9$ & \\
\hline Asialofetuin (ASF)/BHL & BHL & ASF & 1.2 & $37 \pm 3$ & \\
\hline ASF/VAA & VAA & ASF & 1.2 & $43 \pm 5$ & \\
\hline $\mathrm{ASF} / \mathrm{IgG}$ & ASF & $\operatorname{IgG}$ & 1.2 & $45 \pm 6$ & \\
\hline ASF/RCA & ASF & RCA & 1.2 & $65 \pm 9$ & \\
\hline $\begin{array}{l}\text { Nitrilotriacetate (NAT)/ } \\
\text { histidine } 6\left(\mathrm{His}_{6}\right)\end{array}$ & NAT & $\mathrm{His}_{6}$ & $0.09-0.27$ & $150-194$ & $\begin{array}{l}\text { Kienberger et al. } \\
(2000)\end{array}$ \\
\hline Human ocular mucins & Human ocular mucins & $\begin{array}{l}\text { Human ocular } \\
\text { mucins }\end{array}$ & $0.0205-0.3488$ & $100-1200$ & Berry et al. (2001) \\
\hline $\begin{array}{l}\text { Ligand (RGD)/human } \\
\text { platelet } \alpha_{\mathrm{IIb}} \beta_{3} \text { receptor }\end{array}$ & $\begin{array}{l}\text { Human platelet } \alpha_{\mathrm{IIb}} \beta_{3} \\
\text { receptor }\end{array}$ & Ligand (RGD) & 0.2 & 93 & $\begin{array}{l}\text { Lee and Marchant } \\
\text { (2001) }\end{array}$ \\
\hline Phospholipid bilayers/recoverin & Phospholipid bilayer & Recoverin & 5 & $48 \pm 5$ & $\begin{array}{l}\text { Desmeules et al. } \\
\text { (2002) }\end{array}$ \\
\hline $\begin{array}{l}\text { Function-associated antigen-1 } \\
\text { (LFA-1)/intercellular } \\
\text { adhesion molecule-1 (ICAM-1) }\end{array}$ & iICAM-1 & iLFA-1 & $0.1-15$ & Not given & Zhang et al. (2002) \\
\hline $\begin{array}{l}\text { Function-associated antigen-1 } \\
\text { (LFA-1)/intercellular } \\
\text { adhesion molecule-1 (ICAM-1) }\end{array}$ & hICAM-1 & iLFA-1 & $0.1-15$ & Not given & \\
\hline $\begin{array}{l}\text { Ganglioside } \mathrm{G}_{\mathrm{M} 1} / \text { cholera toxin } \\
\text { B-oligomer (ctB) }\end{array}$ & Ganglioside $\mathrm{G}_{\mathrm{M} 1}$ & $\begin{array}{l}\text { Cholera toxin } \\
\text { B-pentamer }(\mathrm{ctB})\end{array}$ & $0.04-4$ & $54 \pm 46-62 \pm 30$ & Cai et al. (2003) \\
\hline $\begin{array}{l}\text { P-selectin/P-selectin glycoprotein } \\
\text { ligand-1 (PSGL-1) }\end{array}$ & P-selectin & PSGL-1 & 0.25 & 20 & Marshall et al. (2003) \\
\hline $\begin{array}{l}\text { Receptor-associated protein } \\
\text { (RAP)/binding protein on } \\
\text { living fibroblast cells }\end{array}$ & $\begin{array}{l}\text { Binding protein } \\
\text { on living fibroblast } \\
\text { cells attached } \\
\text { to surface }\end{array}$ & $\begin{array}{l}\text { Receptor-associated } \\
\text { protein }\end{array}$ & 1 & 120 & Osada et al. (2003) \\
\hline Cell adhesion proteoglycan & Proteoglycans & Proteoglycans & Not given & Not given & Popescu et al. (2003) \\
\hline Epimerase AlgE4/mannuronan & Epimerase AlgE4 & Mannuronan & $0.2-4$ & $74-144$ & Sletmoen et al. (2004) \\
\hline Human $\alpha_{5} \beta_{1}$ integrins/GRGDSP & GRGDSP & $\alpha_{5} \beta_{1}$ Integrins & $1-50$ & $32 \pm 2$ & Kokkoli et al. (2004) \\
\hline
\end{tabular}

contributions from non-specific interactions. Fig. 1B shows a schematic diagram of a typical non-specific interaction. The difference between the curves of Fig. 1A (specific interaction) and Fig. 1B (non-specific interaction) is that Fig. 1A shows a change in the slope during the retraction process which is a result of a decreased effective spring constant. This change indicates that at the beginning of the retraction process, the cantilever is relaxed, while during further retraction, the cantilever as well as the spacer, ligand and protein, become stretched. In contrast, the curve of Fig. 1B retains the same slope during the process of retraction. This is a non-specific interaction between a ligand at the tip and a protein on the substrate without the involvement of spacers, so therefore, we can only assume the cantilever is bent (Willemsen et al., 1998).

Non-specific interactions can arise from an improper spatial orientation of the protein and/or ligand that prohibits specific binding during the approach cycle and/or while in contact. Thus the challenge is to identify those interactions that are specific, as opposed to those that are non-specific, in nature. This separation can be accomplished by conducting control experiments where, for example, the binding site on one of the partners in the protein-ligand or protein-protein pair is blocked. Because of the often random spatial orientation of the binding partners at the tip and substrate surface, it is usually necessary to collect several hundred individual force curves to determine the distribution of the binding force.

Another essential requirement for the quantitative measurement of interaction forces is to develope an accurate method for the calibration of the spring constant, $k$, of the AFM cantilever. Since widely used commercially available silicon nitride cantilevers vary significantly in their spring constant (Cleveland et al., 1993), several methods for calibration of AFM cantilevers have been proposed and used in various laboratories (Cleveland et al., 1993; Hutter and Bechhoefer, 1994; Senden and Ducker, 1994). However, it has been shown that measured values for the spring constants can differ significantly from the original manufacturer's specifications (Cleveland et al., 1993).

In light of the fact that the AFM is now used more frequently as a technique to measure interaction forces, it has become more critical that exact values are measured and determined. However, an important feature of these interaction assays is that 


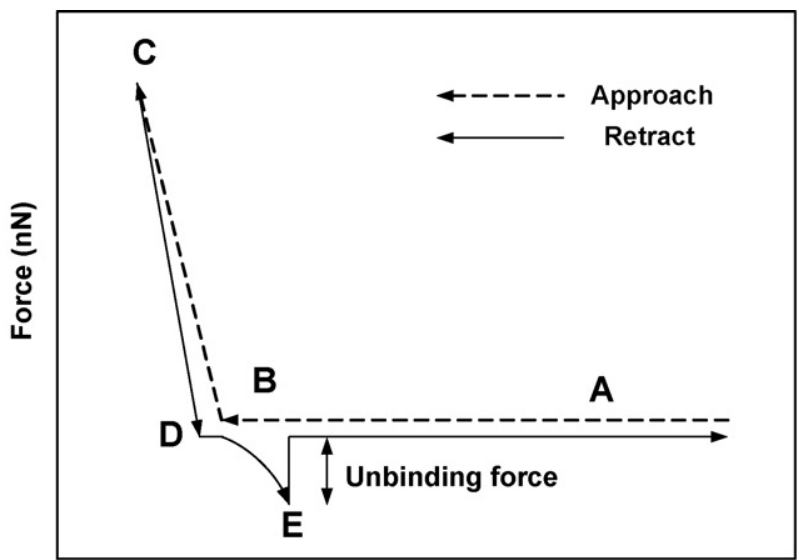

(A)

Distance (nm)

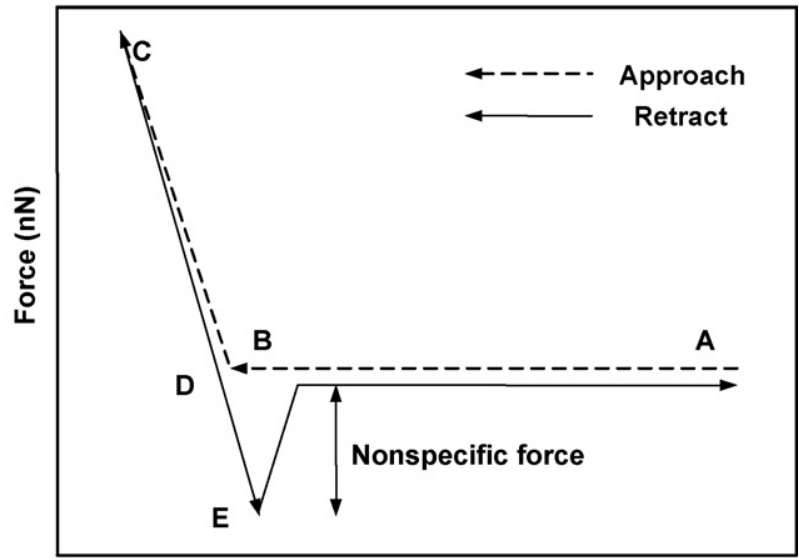

(B)

Distance (nm)

Fig. 1. (A) A schematic diagram of a typical specific force measurement curve, using an AFM to measure the force required to separate individual intermolecular protein-ligand (protein) interaction. Approach (dash line): as the piezoscanner moves towards the AFM tip at a constant velocity from A to B, and then where the AFM tip comes into contact with the surface at point B. As the scanner continues approaching the tip, the cantilever bends upward until it reaches point $\mathrm{C}$. The retract (solid line): occurs when the tip reaches point $\mathrm{C}$, at which the piezo-scanner moves away from the AFM tip and the cantilever then begins to retract. During the retraction process, the tip adheres to the surface due to the interaction between the tip and sample and results in a change in the slope of the curve (points C-D to D-E). As the scanner continues to retract, the cantilever is bent downwards until it reaches point $\mathrm{E}$. The tip-sample starts to break from point E. Finally, the cantilever then returns to its original equilibrium state at point A. (B) A schematic diagram of a typical nonspecific force measurement curve. (A) A change in the slope of the curve (points $\mathrm{C}-\mathrm{D}$ and D-E) during the retraction process. The curve of (B) retains the same slope (points $\mathrm{C}-\mathrm{E}$ ) during the process of retraction.

the measured forces are not contingent only on the nature of the pair, but depend also on the loading rate at which force is applied to the complex. The unbinding force usually scales linearly with the logarithm of the loading rate. For a single a single barrier, this would give rise to a simple, linear force spectrum versus $\ln (r)$ (Fig. 2A). In cases involving more than one barrier, and assuming that all barriers lie along a single, one-dimensional escape path, the spectrum is predicted to follow a continuous sequence of linear regimes (Fig. 2B) (Merkel et al., 1999; Nevo et al., 2003).
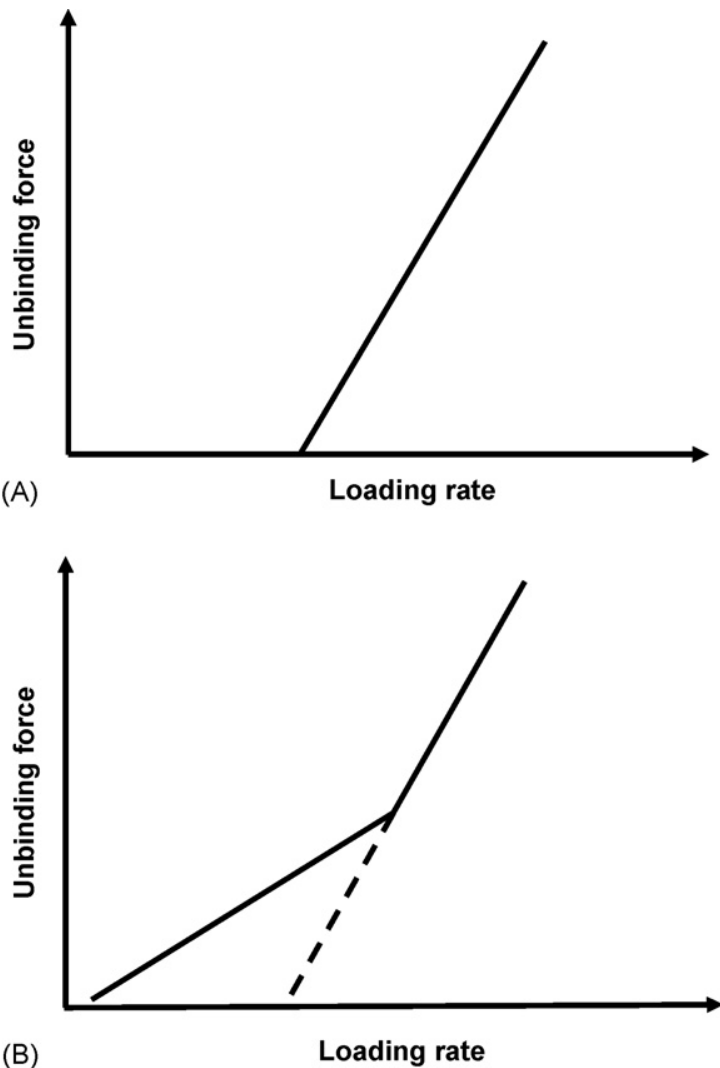

Fig. 2. (A) Dynamic force spectra. The most probable unbinding force vs. the logarithm of the loading rate is a straight line in each regime of the spectrum. (B) A piece-wise linear dynamic force spectrum for a cascade of two sharp energy barriers, which is predicted to follow a continuous sequence of linear regimes.

\subsection{Examples}

\subsubsection{Ran-importin $\beta 1$ interaction}

Nevo et al. (2003) applied AFM to study the interaction of Ran with the nuclear import receptor importin $\beta 1$ (imp $\beta$ ) at the single-molecule level. It was shown that the probability density of rupture events under a ramp of force is described by a random (Markov) process, which predicts the likehood of bond survival over time. The most probable force for unbinding, taken as the maximum of the force distribution, is related to the loading rate through the Eq. (3). They first studied the interaction between imp $\beta$ and Ran loaded with GDP. Next, they investigated the interaction between imp $\beta$ and Ran loaded with the nonhydrolyzable GTP analog GppNHp. In contrast to GDP, which can be readily loaded into Ran, loading GppNHp into Ran is $\sim 80 \%$ efficient, even in the present of alkaline phosphatase. Unbinding of Ran-GppNHp from imp $\beta$ gave rise to a distinct set of force distributions, which were shifted to higher forces compared with those measured for Ran-GDP-imp $\beta$. These distributions were proven to have a unique bimodal appearance (Fig. 3A). Moreover, a semilog plot of the most probable unbinding forces measured for each of the two populations was also shown (Fig. 3B). Those results indicate that interaction between RanGppNHp and imp $\beta$ could lead to two distinct bound states, each associated with a dissociation path of its own. 

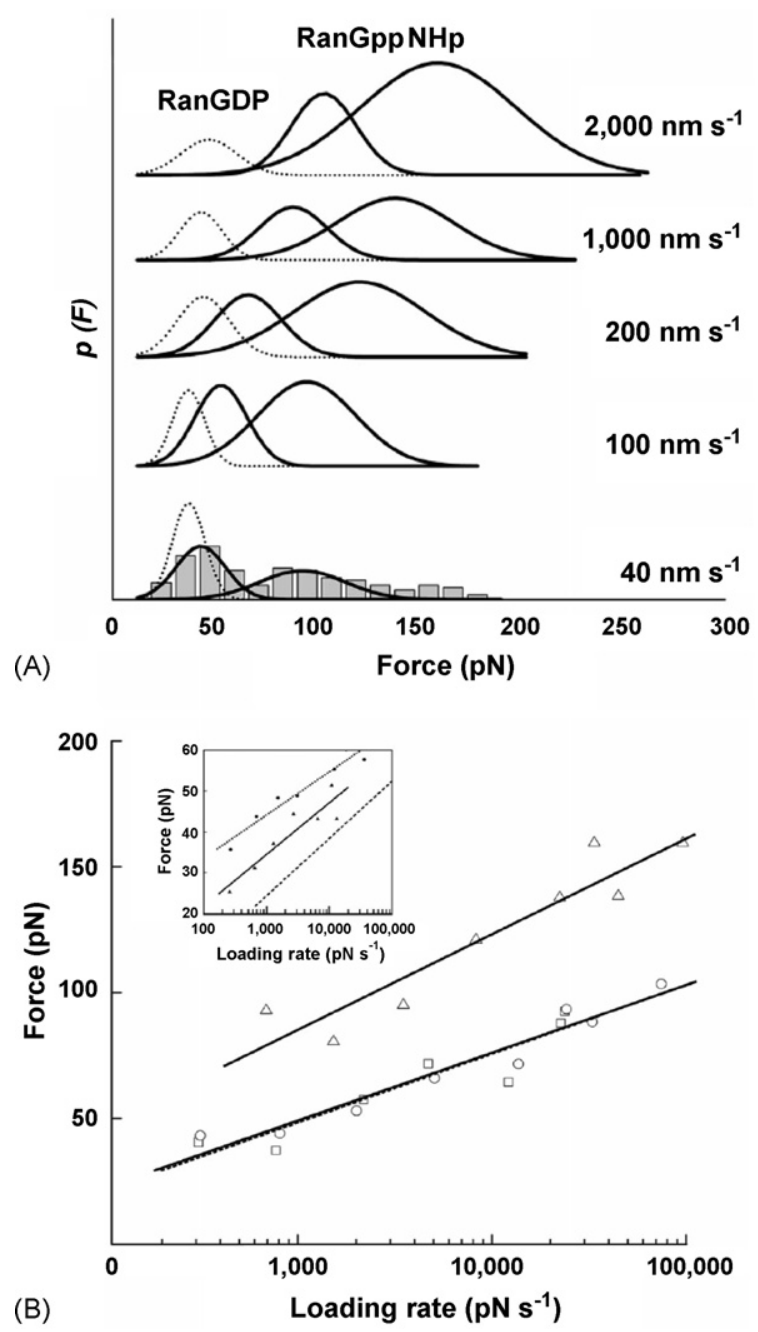

Fig. 3. Molecular unbinding of different Ran-imp $\beta$ complexes. (A) Unbinding force distributions. To reveal dynamic aspects of bond rupture, measurements were carried out at various probe velocities, leading to different loading rates. (B) Force spectra. Shown in the main figure are plots for the two populations observed for Ran-GppNHp-imp $\beta$ (solid lines) and the single population observed for RanQ69L-GTP-imp $\beta$ (dotted line). Inset, curves obtained for Ran-GDP-impß (solid line) and RanQ69L-imp $\beta$ (dotted line); dashed line describes noise level. Reprinted with permission from Nevo et al. (2003). Copyright 2003 Nature Publishing Group.

\subsubsection{Mercaptopropanoic acid derivative (MPAD)-anti- MPAD interaction}

Kaur et al. (2004) used an AFM to directly evaluate specific interaction forces between pesticides and antibodies on a biosensor surface. An oriented immobilization of antibodies against two herbicide molecule mercaptopropanoic acid derivatives of atrazine (MPAD) and 2,4-dichlorophenoxyacetic acid $(2,4-\mathrm{D})$ on a gold substrate, was carried out to simulate an immuno-biosensor surface. The adhesive force between the immobilized antibodies and their respective antigens was measured by force spectroscopy using a hapten-carrier protein functionalized AFM cantilever. They demonstrated typical force-distance curves for the interaction between the BSAMPAD and BSA-2,4-D functionalized cantilevers with a corresponding antibody as well as only protein A-coated surfaces. The interaction between the anti-atrazine antibody and BSA-atrazine-coated cantilevers showed a wide range distribution value of the pull-off force, varying from 200 to $940 \mathrm{pN}$ with the majority of the data falling between 200 and $500 \mathrm{pN}$. The mean value was calculated to be $511.62 \pm$ $244.1 \mathrm{pN}$ (S.D.). This mean value was significantly lower $(P<0.001)$ when the BSA-atrazine-coated cantilever was allowed to interact with only the protein A-coated surface $(31.56 \pm 19.8 \mathrm{pN})$. Furthermore, in the case of the BSA-2,4-Dcoated cantilevers, the pull-off force with the anti-2,4-D-coated surface varied from between 80 and $700 \mathrm{pN}$. The mean value of $228.62 \pm 163.1 \mathrm{pN}$ was significantly higher $(P<0.001)$ than the corresponding value of $25.66 \pm 33.5 \mathrm{pN}$ for the BSA-2,4-D interaction with protein A.

\subsubsection{Receptor-associated protein (RAP)-receptor on fibroblast cells}

Osada et al. (2003) used an AFM to examine the distribution of the receptor-associated protein (RAP) binding protein and the adhesion force between a RAP and its binding protein on living fibroblast cells. The distribution of the RAP binding protein was obtained at $256(16 \times 16)$ locations in $2 \mu \mathrm{m} \times$ $2 \mu \mathrm{m}$ sections over the surface of the living cells. They also measured the adhesion forces between the RAP and the binding protein with an AFM tip functionalized with RAP. It was found that the most frequently observed force value was $120 \mathrm{pN}$. In the presence of RAP in the scanning solution, the force curves showed a large decrease of adhesion force. The results indicated that the measured adhesive forces represent specific binding between the RAP and the binding protein.

\subsubsection{Epimerase AlgE4-mannuronan interaction}

Sletmoen et al. (2004) determined the interaction between AlgE4 epimerase and mannuronan by dynamic force spectroscopy. Alginate biosynthesis involves C-5-mannuronan epimerases catalyzing the conversion of $\beta$-D-mannuronic acid to $\alpha$-L-guluronic acid at a polymer level. It is known that mannuronan epimerases are modular enzymes where their various modules can yield specific sequential patterns of the converted residues in their polymer products. Sletmoen et al. (2004) studied the specific unbinding force between the molecular pairs of mannuronan and AlgE4 as well as its two modules, A and R, respectively, as a function of the force loading rate. They found that the mean protein-mannuronan unbinding force was in the range $73-144 \mathrm{pN}$ depending on the protein, and possessing an loading rate of $0.6 \mathrm{nN} / \mathrm{s}$ which increased with an increased loading rate. Moreover, the position of the activation barrier was determined to be $0.23 \pm 0.04 \mathrm{~nm}$ for the AlgE4 and $0.10 \pm 0.02 \mathrm{~nm}$ for its A-module. The lack of interaction observed between the R-module and mannuronan suggests that the A-module contains the binding site for the polymer substrate.

\subsubsection{Glucagon-anti-glucagon interaction}

Lin et al. (in press) studied the dynamic responses of glucagon/anti-glucagon pairs with multiple pull-off steps to pulling velocity and $\mathrm{pH}$ by AFM. Force-distance curves of a specific glucagons-anti-glucagon interaction system with 


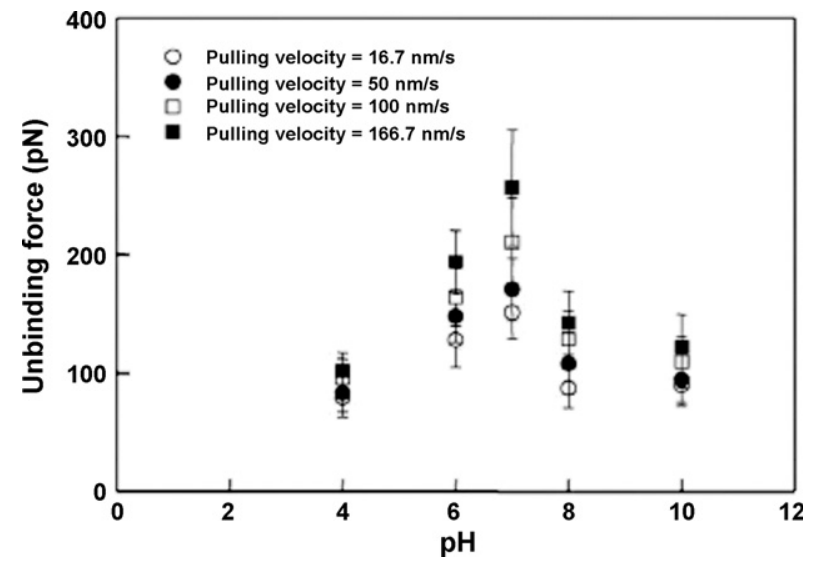

Fig. 4. $\mathrm{pH}$ dependence of the unbinding force for glucagons-anti-glucagon pairs with different pulling velocities $(16.7-166.7 \mathrm{~nm} / \mathrm{s})$. Reprinted with permission from Lin et al. (in press). Copyright 2006 Elsevier Ltd.

mono-, di-, and multi-unbinding events were recorded, which were attributed to a single, sequential or multiple breaking of interacting bond(s) between glucagon and anti-glucagon. They reported the dynamic response of glucagons-anti-glucagon pairs to various pulling velocities $(16.7-166.7 \mathrm{~nm} / \mathrm{s})$. It was found that the mean value of the unbinding force was shifted toward higher values with increasing pulling velocity at $\mathrm{pH} 7$. Moreover, the dynamic response of glucagons-anti-glucagon pairs to $\mathrm{pH}$ (4-10) with different pulling velocities was reported. Within the acid range, the bond strength between the glucagon/anti-glucagon complex showed a rapid increase from $\mathrm{pH} 4$ to 7 and reached a maximum $(256.4 \pm 48.9 \mathrm{pN}$ at $166.7 \mathrm{~nm} / \mathrm{s}$ ) at neutrality, followed by a sharp decrease with increasing pH (7-10) (Fig. 4). This study demonstrated that the $\mathrm{pH}$ dependence of multiple antigen-antibody bond-rupture forces could be measured by a force-based AFM biosensor.

\section{Determination of dissociation rate}

\subsection{Introduction}

The dissociate rate (i.e. off rate) $k_{\text {off }}$ can be determined by the strength of the bonds which affects the activation energy barrier for dissociation and by the thermal energy $k_{\mathrm{B}} T$, where $k_{\mathrm{B}}$ is the Boltzmann constant. The activation energy for the dissociation is the difference in energy between the initial state and the transition state of the highest energy to which the system must be raised before dissociation can occur. It is important that we understand the binding of a ligand to its macromolecular protein receptor, not only for its fundamental importance but also as an aid in designing new potential drug candidates. Recent data of dissociation rates from thermodynamic and kinetic measurements have been supplemented by single-molecule experiments using AFM, in which an external force is applied to dissociate the protein-ligand complex (Table 2). Moreover, molecular dynamic simulations (Grubmuller et al., 1996) that complement the original AFM analysis of the protein-ligand also give some insights into the interactions along the dissociation path (Florin et al., 1994; Moy et al., 1994).

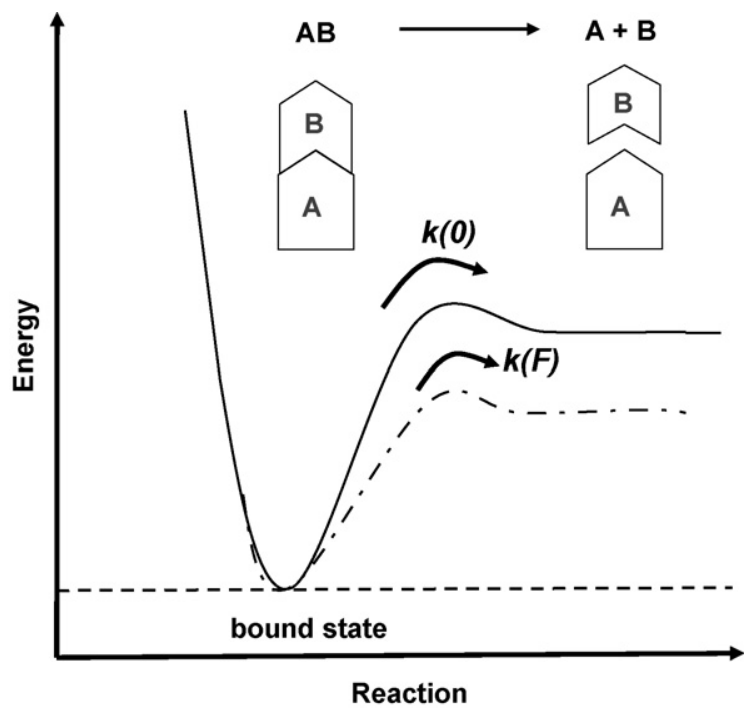

Fig. 5. A schematic diagram of the energy landscape shows the dissociation without an external force (solid line) and with an applied force (dashed line). The intermolecular dissociation without an external force and with an applied force corresponds to the dynamic parameters, $k(0)$ and $k(F)$.

\subsection{Theory}

It is known that a bound state can be idealized by confiding a single energy barrier at a given position along a specific reaction path (Fig. 5). Assuming that the kinetics of the forced unbinding can be analyzed in the context of the Kramer's theory for activated processes (Kramers, 1940), the zero kinetic off rate (dissociation rate) for unbinding can be written as

$k_{\text {off }}(0)=w \mathrm{e}^{-\Delta E / k_{\mathrm{B}} T}$

where $k_{\mathrm{B}}$ is the Boltzmann constant, $T$ the absolute temperature, $k_{\mathrm{B}} T$ represents the thermal energy $\left(4.14 \times 10^{-21} \mathrm{~J}\right), w$ the frequency prefactor, and $\Delta E$ is the activation energy.

In AFM measurements, an external force is usually applied to a pair of atoms that are then pulled apart. Since the timescale

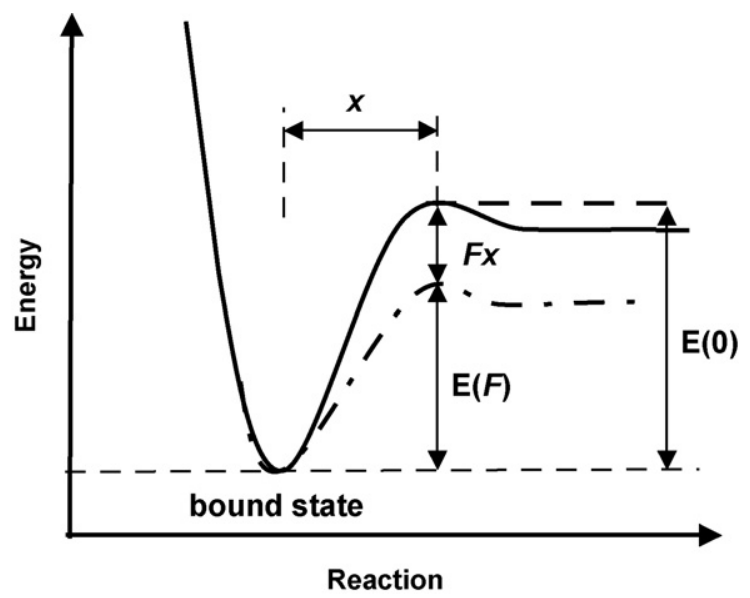

Fig. 6. The schematic diagram of the dissociation over a sharp energy barrier without an external force (solid line) and with an applied force (dashed line). The dissociation over a sharp energy is characterized by an exponential increase of the barrier which is located at a distance, projected along the direction of the applied force. 
Table 2

Protein-ligand off rate and binding energy

\begin{tabular}{|c|c|c|c|c|c|}
\hline Molecular partners & $\begin{array}{l}\text { Loading rate } \\
\left(\mathrm{pN} \mathrm{s}^{-1}\right)\end{array}$ & $\begin{array}{l}\text { Effective bond } \\
\text { length }(\mathrm{nm})\end{array}$ & Off rate $\left(s^{-1}\right)$ & $\begin{array}{l}\text { Binding } \\
\text { energy }\left(k_{\mathrm{B}} T\right)^{\mathrm{a}}\end{array}$ & Reference \\
\hline $\begin{array}{l}\text { Human serum albumin } \\
\text { (HSA)/anti-HAS }\end{array}$ & Not given & 6 & $6.7 \times 10^{-4}$ & Not given & $\begin{array}{l}\text { Hinterdorfer et al. } \\
(1996)\end{array}$ \\
\hline $\begin{array}{l}\text { Concanavalin A (ConA) } \\
\text { receptor/ConA }\end{array}$ & $415-4980$ & 0.27 & 0.17 & Not given & $\begin{array}{l}\text { Chen and Moy } \\
(2000)\end{array}$ \\
\hline Lactose/bovine heart (BHL) & $20-10,000$ & $1.02 \pm 0.17$ & 0.09 & Not given & Dettmann et al. \\
\hline $\begin{array}{l}\text { Lactose/lactose-binding } \\
\text { immunoglobulin G (IgG) }\end{array}$ & $20-10,000$ & $0.72 \pm 0.09$ & 0.9 & Not given & $(2000)$ \\
\hline Lactose/Viscum album (VAA) & $20-10,000$ & $0.75 \pm 0.16$ & 0.09 & Not given & \\
\hline Lactose/Ricinus communis (RCA) & $20-10,000$ & $0.41 \pm 0.07$ & 0.8 & Not given & \\
\hline Asialofetuin (ASF)/BHL & $20-10,000$ & $0.62 \pm 0.06$ & 1.3 & Not given & \\
\hline ASF/VAA & $20-10,000$ & $0.60 \pm 0.17$ & 0.9 & Not given & \\
\hline ASF/IgG & $20-10,000$ & $0.48 \pm 0.07$ & 1.6 & Not given & \\
\hline ASF/RCA & $20-10,000$ & $0.41 \pm 0.07$ & 0.4 & Not given & \\
\hline Streptavidin/biotin & $\begin{array}{l}100-1000 \\
1000-5000\end{array}$ & $\begin{array}{l}0.49 \\
0.05\end{array}$ & $\begin{array}{l}1.67 \times 10^{-5} \\
2.09\end{array}$ & Not given & Yuan et al. (2000) \\
\hline $\begin{array}{l}\text { Streptavidin mutant } \\
(\mathrm{W} 120 \mathrm{~F}) / \text { biotin }\end{array}$ & $\begin{array}{l}100-1000 \\
1000-5000\end{array}$ & $\begin{array}{l}0.31 \\
0.11\end{array}$ & $\begin{array}{l}6.70 \times 10^{-3} \\
1.05\end{array}$ & Not given & \\
\hline Streptavidin/biotin & $\begin{array}{l}0.05-60,000 \\
40,000-80,000\end{array}$ & $\begin{array}{l}0.5 \\
0.12\end{array}$ & $\begin{array}{l}\sim 10^{-2} \\
\sim 30\end{array}$ & Not given & Lo et al. (2001) \\
\hline $\begin{array}{r}\text { Ryanodine receptor } 1 \\
\text { (RYR1)/anti-RYR1 }\end{array}$ & $42-2000$ & 0.2 & 12.7 & Not given & $\begin{array}{l}\text { Kada et al. } \\
(2001)\end{array}$ \\
\hline $\begin{array}{l}\text { Ligand (RGD)/human platelet } \\
\alpha_{\mathrm{IIb}} \beta_{3} \text { receptor }\end{array}$ & $10,000-50,000$ & 0.1 & 22.6 & -6.37 & $\begin{array}{l}\text { Lee and Marchant } \\
\text { (2001) }\end{array}$ \\
\hline $\begin{array}{l}\text { Low-affinity } \\
\text { function-associated antigen-1 } \\
\text { (1LFA-1)/intercellular } \\
\text { adhesion molecule-1 (ICAM-1) }\end{array}$ & $\begin{array}{l}20-10,000 \\
10,000-50,000\end{array}$ & $\begin{array}{l}0.15 \\
0.018\end{array}$ & $\begin{array}{l}4 \\
57\end{array}$ & 9.2 & $\begin{array}{l}\text { Zhang et al. } \\
(2002)\end{array}$ \\
\hline $\begin{array}{l}\text { High-affinity } \\
\text { function-associated antigen-1 } \\
\text { (hLFA-1)/intercellular } \\
\text { adhesion molecule-1 (ICAM-1) }\end{array}$ & $\begin{array}{l}20-10,000 \\
10,000-50,000\end{array}$ & $\begin{array}{l}0.21 \\
0.024\end{array}$ & $\begin{array}{l}0.17 \\
40\end{array}$ & 14.8 & \\
\hline $\begin{array}{l}\text { Ganglioside } \mathrm{G}_{\mathrm{M} 1} / \text { cholera } \\
\text { toxin B-oligomer (ctB) }\end{array}$ & Not given & 0.25 & Not given & 4.7 & Cai et al. (2003) \\
\hline Fibrinogen $\left(\alpha_{\mathrm{IIb}} \beta_{3}\right) / \mathrm{RGD}$ & $100-1,000,000$ & 0.103 & 1.5 & $-6.4\left(-2.64 \times 10^{-20} \mathrm{~J}\right)$ & Lee and Marchant \\
\hline $\begin{array}{l}\text { Fibrinogen }\left(\alpha_{\mathrm{IIb}} \beta_{3}\right) / \\
\text { HHLGGAKQAGDV }\end{array}$ & $100-1,000,000$ & 0.109 & 47.58 & $6.5\left(2.67 \times 10^{-20} \mathrm{~J}\right)$ & $(2003)$ \\
\hline Human $\alpha_{5} \beta_{1}$ integrins/GRGDSP & $\begin{array}{l}\text { Above } 59,000 \\
\text { Below 59,000 }\end{array}$ & $\begin{array}{l}0.09 \\
2.77\end{array}$ & $\begin{array}{l}787 \\
0.015\end{array}$ & Not given & $\begin{array}{l}\text { Kokkoli et al. } \\
\text { (2004) }\end{array}$ \\
\hline $\begin{array}{l}\text { Sendai-purple membrane } \\
\text { (Sendai-PM)/anti-Sendai } \\
\text { antibody }\end{array}$ & $2000-50,000$ & 0.12 & 6 & Not given & $\begin{array}{l}\text { Kienberger et al. } \\
(2005)\end{array}$ \\
\hline
\end{tabular}

${ }^{\mathrm{a}} k_{\mathrm{B}}$ : Boltzmann constant $=1.381 \times 10^{-23} \mathrm{~J} ; T$ : room temperature $=278 \mathrm{~K}$.

of the thermal motion and the time scale of the force variation in the AFM experiment are separated by at least several orders of magnitude, the assumption is usually made that the effect of the external force on the microscope kinetics is that of a constant force. As was first argued by Bell (1978), a constant force $F$ applied to $x$ modifies the energy (and the free energy) by a factor $F x$. Thus, if $F$ and $x$ are parallel (Fig. 6), then

$$
\Delta E(F)=\Delta E-F x
$$

which establishes a rate for unbinding that depends on the applied force such that

$k_{\text {off }}(F)=k_{\text {off }}(0) \exp \left[\frac{F x}{k_{\mathrm{B}} T}\right]$ where it can be assumed that $k_{\text {off }}$ (Eq. (4)) and the prefactor $w$ is not affected by the force.

\subsection{Measurements}

Kinetic parameters can be extracted from AFM data using theories developed above to understand bond dissociation, including protein-ligand dissociation under applied external forces. The kinetic rate-off $k_{\text {off }}(f)$ (Eq. (6)) is an essential determinant of the molecular interaction as it can provide insight into the strength of bonds, the occurrence of bonds, and the bond relaxation time. We can determine the $k_{\text {off }}(f)$ value from the unbinding force by looking at the range of the loading rate for protein-ligand unbinding events. Although an AFM is capable of applying a loading rate ranging between 10 and 
$1000 \mathrm{nN} / \mathrm{s}$, instability at rates $>100 \mathrm{nN} / \mathrm{s}$ due to hydrodynamic effect is often experienced for protein-ligand measurements (Lee and Marchant, 2003).

Experimentally, the plot of unbinding force versus the logarithm of the loading rate (i.e. the product of the force constant of the AFM cantilever and its retraction speed) (Schwesinger et al., 2000) can be employed to estimate the dissociation rate (zero kinetic off-rate $k_{\mathrm{off}}(0)$ ) at zero force.

\subsection{Examples}

\subsubsection{Concanavalin A (ConA) receptor-ConA interaction}

In 2000, Chen and Moy used an AFM to determine whether receptor cross-linking can increase cell adhesion through enhanced cooperative binding. They used the AFM to obtain force measurements before and after chemically cross-linking adhesion receptors on the surface of fibroblast cells. They measured the adhesive strength between concanavalin A (ConA) coupled to an AFM tip and ConA receptors on the surface of the NIH3T3 fibroblast cells. Their results showed that cross-linking of the receptors with either glutaraldehyde or 3,3'-dithio-bis(sulfosuccinimidylproprionate) led to an increase in adhesion that can be attributed to enhanced cooperativity among the adhesion complexes. Moreover, to determine if changes in the loading rate contributed to the increased ConA/ ConA receptor adhesion, they obtained force measurements for the breakage of individual ConA and D-mannose complexes over a range encompassing the observed loading rates of unfixed and fixed cell measurements. For these previous experiments, the adhesive strength was determined at different force loading rates, and the force histograms were acquired from measurements carried out using a ConA-functionalized tip on a D-mannose-linked agarose bead. In addition, the rupture force $f^{*}$ was dependent on the loading rate $r_{\mathrm{f}}$ obtained and the dissociation rate constant was calculated from the Bell's model. According to the Bell's and Evans model, the dissociation rate can be obtained from the plot of $f^{*}$ versus $\log \left(r_{\mathrm{f}}\right)$ to be $0.17 \mathrm{~s}^{-1}$, more information as described in Section 3.2. This investigation demonstrated that the cross-linking of surface receptors caused a shift towards cooperative binding and hence results in an increase in the receptor binding strength.

\subsubsection{Ryanodine receptor 1 ( $R Y R 1)$-anti-RYRI interaction}

In 2000, Kada et al. adsorbed the skeletal muscle $\mathrm{Ca}^{2+}$ released channel (ryanodine receptor 1, RYR1) to a mica substrate with the cytoplasmic side facing up. They found that a single specific RYR1-anti-RYR1 recognition event can be detected at the single-molecule level with AFM tips to which the anti-RYR1 was tethered. In linear scans, the occurrence of the RYR1-anti-RYR1 binding showed a significant lateral dependence, which allowed for the localization of the binding sites with a $\mathrm{nm}$ resolution. Variation of the loading rate in the force spectroscopy experiments revealed a logarithmic dependence of the unbinding forces, ranging from $42 \mathrm{pN}$ at $2 \mathrm{nN} / \mathrm{s}$ to $73 \mathrm{pN}$ at $9 \mathrm{nN} / \mathrm{s}$. As we know from theoretical predictions (Grubmuller et al., 1996; Evans and Ritchie, 1997), the unbinding force $f$ will rise linearly with the loading rate on a half-logarithmic scale, which is characteristic for a single-energy barrier in the thermally
(A)
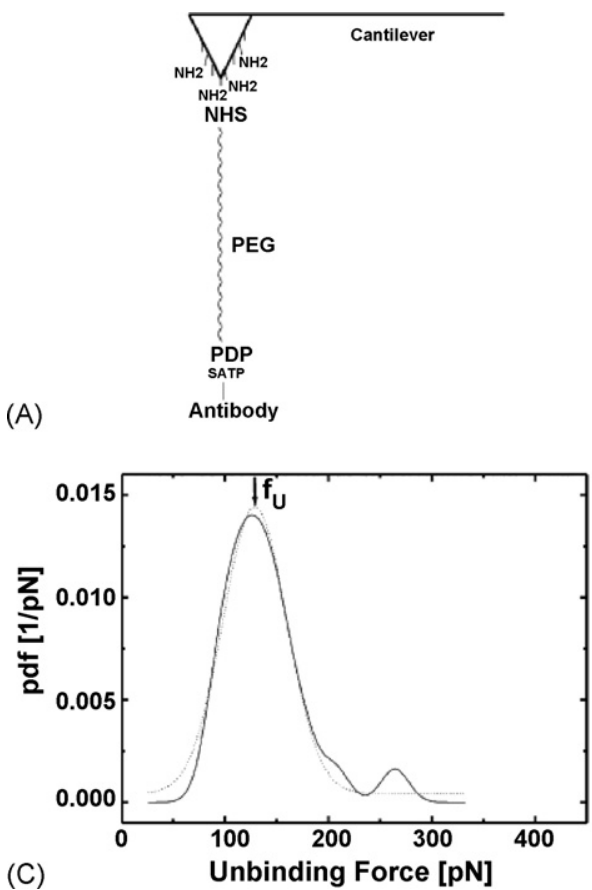
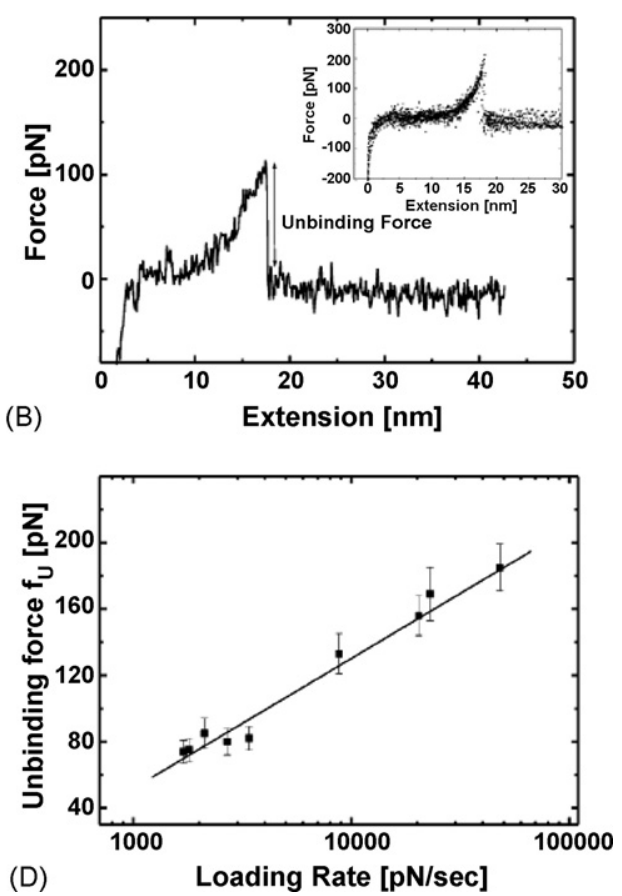

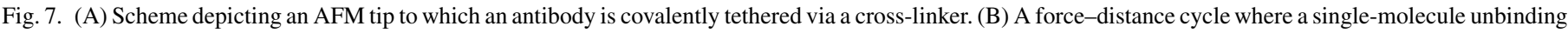

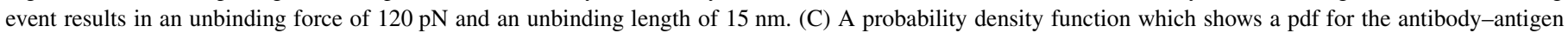

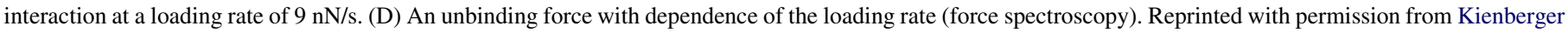
et al. (2005). Copyright 2005 Elsevier Ltd. 
activated regime (Merkel et al., 1999). The bond length of $L=0.2 \mathrm{~nm}$ and the dissociation rate constant of $k_{\text {off }}=12.7 \mathrm{~s}^{-1}$ were determined using Eq. (3) where the slope and intercept is at zero force.

\subsubsection{Human $\alpha_{5} \beta_{1}$ integrins-GRGDSP dissociation}

In 2004, with an AFM, Kokkoli et al. engineered a novel bio-mimetic system to study the mechanistic details of the unbinding processes of $\alpha_{5} \beta_{1}-$ GRGDSP pairs at collective and the single-molecule level. Their investigation demonstrated for the first time that at a collective level, the separation of multiple identical bonds within $\alpha_{5} \beta_{1}-$ GRGDSP, is a combination of multiple unbinding events as the pair does not break at once but in multiple steps, and in a stretching process. Force histograms were collected at a loading rate of $1-305 \mathrm{nN} / \mathrm{s}$. The bond strength at a specific loading rate can be estimated by inspecting the force histogram and by calculating the autocorrelation function for the histogram. Moreover, the unbinding force versus the logarithm of the loading rate for a single $\alpha_{5} \beta_{1}-$ GRGDSP bond can be plotted. The force spectrum revealed two linear regimes with different slopes within the range of the loading rates that were examined, and the Bell parameters $\left(x_{\mathrm{B}}\right.$ and $\left.k_{\text {off }}^{0}\right)$ were also estimated from the slope and the intercept of force versus the logarithm of the loading rate (Evans and Ritchie, 1997; Tees et al., 2001). The best fit to the data revealed an inner barrier for the loading rates which was seen at a value above $59 \mathrm{nN} / \mathrm{s}$ at $x_{\mathrm{B}}=0.09 \mathrm{~nm}$ that is characterized by a very rapid unstressed transition rate of $1 / t_{\text {off }}=787 \mathrm{~s}^{-1}$. For a value below $59 \mathrm{nN} / \mathrm{s}$, a second regime appeared in the force spectrum that mapped an outer barrier at $x_{\mathrm{B}}=2.77 \mathrm{~nm}$. This outer barrier is characterized by a much slower transition rate that defines the dissociation rate constant $k_{\text {off }}^{0}$ in the absence of force, $k_{\mathrm{off}}^{0}=0.015 \mathrm{~s}^{-1}$. This value is in good agreement with the dissociation rate constant of $0.01 \mathrm{~s}^{-1}$ as reported between the fibronectin and fibronectin receptor $\left(\alpha_{5} \beta_{1}\right)$ on the fibroblast cells in the solution.

\subsubsection{Sendai-purple membrane (Sendai-PM)-anti-Sendai interaction}

Kienberger et al. (2005) investigated the molecular recognition of antibodies to membrane-antigens and the extraction of the antigens out of the membranes at a singlemolecular level. Dynamic force microscopy imaging and enzyme immunoassay was used to detect the binding of the anti-Sendai antibodies to Sendai-epitopes genetically fused into bacteriorhodopsin molecules from the purple membranes under physiological conditions. Moreover, they measured the unbinding force $f_{\mathrm{u}}$ as a function of the loading rate $r$ (Fig. 7). The dissociation rate constant $\left(k_{\text {off }}^{0}\right)$ was determined from the slope and the intercept of force versus the logarithm of the loading rate (Evans and Ritchie, 1997, 1999; Kerkel et al., 1999). The Sendai-anti-Sendai interaction strength of 70 $170 \mathrm{pN}$ at loading rates of 2-50 nN/s yielded a barrier width of $x=0.12 \mathrm{~nm}$ and a kinetic dissociation rate (off-rate) (corresponding to the barrier height) of $k_{\mathrm{off}}=6 \mathrm{~s}^{-1}$, respectively.

\section{Determination of energy barriers}

\subsection{Introduction}

Similar to other non-covalent associations, a protein-ligand interaction has a limited bond association lifetime. Thus, experimental unbinding force measurements will fail, for any given applied tensional force, if the measurement time exceeds the bond association lifetime. This means that an unbinding force will have no strength on time scales longer than its natural lifetime for entropy-driven dissociation. Therefore, the strength of a bond will depend on how the external force is applied over time. As AFM measurement of an unbinding force requires a finite time, the history of loading can be parameterized as a ramp in time as set by a constant loading rate, where the loading rate equals the cantilever/probe stiffness multiplied by speed. However, an AFM measurement of the unbinding force is not in itself a useful measure of bio-molecular interactions. Fortunately, AFM measurements can be transformed into useful thermodynamic and kinetic parameters. In the literature, it has been reported that AFM force measurements of protein-ligand unbinding can be correlated with the enthalpic activation barrier for ligand dissociation (Chilkoti et al., 1995; Lee and Marchant, 2001, 2003; Zhang et al., 2002; Cai et al., 2003). Such insight can be achieved by repeating experiments over a range of loading rates over $10-1000 \mathrm{nN} / \mathrm{s}$. The molecular binding energies between protein-specific ligands and surfacebound proteins have been recently measured using an AFM (see Table 2).

\subsection{Theory}

Under an AFM dynamic force spectrum for protein-ligand unbinding, the most probable unbinding force $F$ versus $\log _{\mathrm{e}}$ (loading rate $=r$ ) is a straight line in each regime of the spectrum with a slope $f_{\beta}=k_{\mathrm{B}} T / x$ as set by the projected location of the barrier $x$ along the direction of the force. Together with the thermal force $f_{\beta}$, the microscopic attempt frequency $w$ and height $E$ of the activation barrier determine the intrinsic scale for the loading rate based on Eqs. (3) and (4) where

$$
r_{F=0}=w f_{\mathrm{B}} \exp \left(-\frac{E}{k_{\mathrm{B}} T}\right)
$$

The spectrum for a single-sharp energy barrier (Fig. 2A) where the logarithmic intercept at a zero force can be used to deduce the activation barrier height $E$ (Fig. 8A) given an estimate for the microscopic diffusion time such that

$\frac{E}{k_{\mathrm{B}} T}=-\ln \left(r_{F=0}\right)+\ln \left(f_{\mathrm{B}} w\right) \approx-\ln \left(r_{F=0}\right)+\ln \left(f_{\mathrm{B}}\right)$

The most idealized view of a complex molecular energy landscape is a cascade of sharp activation barriers, which leads to a staircase of an exponential increase in the rate constant under force. Using this approach, the most likely force versus $\log _{\mathrm{e}}$ (loading rate) is predicted to follow a simple spectrum of piece-wise continuously linear regime with ascending slopes, 

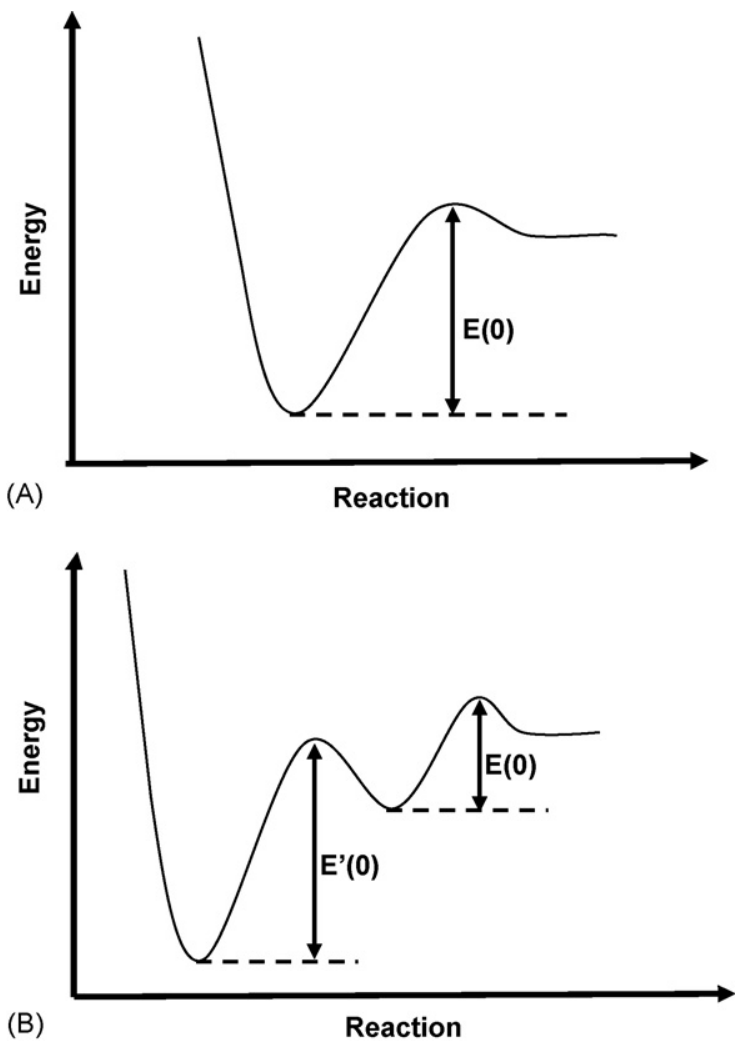

Fig. 8. (A) A conceptual energy landscape for a single sharp activation barrier with an applied force. (B) A conceptual energy landscape for a cascade of barriers with an applied force. The inner barrier emerges to dominate the kinetics when the outer barrier is driven below it by $\geq k_{\mathrm{B}} T$.

as shown in Fig. 2B. Fig. 2B shows a piece-wise linear spectrum for a cascade of two sharp energy barriers. The abrupt increase in slope from one thermal force scale to the next shows that the outer barrier has been suppressed and that the inner barrier has become the dominant kinetic impedance to the detachment (Fig. 8B). The difference between logarithmic intercepts reflects the splitting in the barrier energies adjusted by the ratio of the thermal force scales:

$\frac{\Delta E}{k_{\mathrm{B}} T} \approx-\Delta \ln \left(r_{F=0}\right)^{*}+\Delta \ln \left(f_{\beta}\right)$

\subsection{Measurements}

The single molecular binding energy for protein-ligand interactions, may be extracted from a plot of the unbinding force versus the logarithm of the loading rate. Eq. (8) shows the dynamic properties of a system consisting of a single activation barrier. The most probable unbinding force versus loading rate is a straight line in each regime of the spectrum where the logarithmic intercept at a zero force can be used to deduce the barrier energy $E$, as illustrated in Fig. 7A. As determined by the ratio of the barrier energy $E$ to thermal energy $k_{\mathrm{B}} T$, the linear regime can span an order of magnitude in rate. The slope $f_{\beta}$ maps the microscopic transition state to a thermally averaged distance $x$ along the direction of the force. A barrier energy and microscopic scale for loading rate $f_{\beta} w$ governs the intercept at zero force. In other words, the barrier energy can be inferred from the intercept $\ln \left(r_{F=0}\right)$ at a zero force and by the slope $f_{\beta}$ by, $E / k_{\mathrm{B}} T \approx-\ln \left(r_{F=0}\right)+\ln \left(f_{\beta}\right)$.

Extending this single activation barrier mode to a more complex energy landscape, the signature of a cascade of a sharp activation barrier is a piece-wise continuous sequence of linear regimes with ascending slopes as seen in Fig. 8A. The abrupt increase in slope from one thermal force scale to the next shows that the outer barrier has been suppressed by force and the inner barrier thus becomes the dominant kinetic impedance to the detachment (Fig. 8B) (Evans, 1999; Evans et al., 2001). The dynamic crossover occurs at slightly higher forces than the stationary crossover $(\Delta E / \Delta x)$ in a rate constant as approximated by $\Delta E / \Delta x+k_{\mathrm{B}} T\left[\ln \left(x^{\prime} / x\right)\right] / \Delta x$ where $\Delta x=x^{\prime}-x$ and $\Delta E=E^{\prime}-E$ are different between properties of the adjacent barriers.

\subsection{Examples}

\subsubsection{Human platelet $\alpha_{I I b} \beta_{3}$ receptor-ligand (RGD) interaction}

In 2001, Lee and Marchant measured the debonding interaction between an arginine-glycine-aspartate (RGD) peptide-modified AFM probe tip and a human platelet surface from a $\mathrm{pN}$ to a $\mathrm{nN}$ level of force. Direct measurements of the debonding force for the RGD ligand $-\alpha_{\text {IIb }} \beta_{3}$ platelet receptor system were carried out in a Tyrode buffer at room temperature. The results showed three distinct distributions of debonding forces at a loading rate of $12 \mathrm{nN} / \mathrm{s}$, from which they estimate the debonding force for the single ligand-receptor to be $\sim 93 \mathrm{pN}$. The results obtained also showed evidence for considerable extension in the flexible sample surface during the debonding process, and a linear correlation between the debonding force and the logarithm of the rate of loading. Moreover, they extracted from the AFM data three kinetic parameters, i.e., a single molecular binding energy $E_{\mathrm{b}}$, a zero kinetic off-rate $k_{\text {off }}(0)$, and a transition state $x_{\mathrm{B}}$, based on theories developed by Evans and Ritchie $(1997,1999)$ to understand bond dissociation, including ligand-receptor dissociation under applied external forces. Finally, from Eq. (3) a single molecular binding energy $E_{\mathrm{b}}$, a zero kinetic off-rate $k_{\text {off }}(0)$, and a transition state $x_{\mathrm{B}}$, were extracted from the data, and determined to be $-2.64 \times 10^{-20} \mathrm{~J}, 22.6 \mathrm{~s}^{-1}$ and $0.1 \mathrm{~nm}$, respectively.

\subsubsection{Function-associated antigen-1-intercellular adhesion molecule-1 interaction}

The interaction between leukocyte function-associated antigen-1 (LFA-1) with its cognate ligand intercellular adhesion molecule-1 (ICAM-1) plays a crucial role in leukocyte adhesion. Zhang et al. (2002) reported on AFM measurements of unbinding LFA-1 from ICAM-1. The singlemolecule measurements revealed an energy landscape corresponding to the dissociation of a LFA-1/ICAM-1 complex and provided the basis for defining the energetic determinants of the complex at equilibrium and under the influence of an external force. They performed AFM force measurements in an 
experimental system consisting of an LFA-1-expressing T cell hybridoma, 3A9, attached to the end of an AFM cantilever and an opposing surface expressing ICAM-1. In measurements covering three orders of magnitude change in the force loading rate, the LFA-1/ICAM-1 force spectrum (i.e., unbinding force versus loading rate) revealed a fast and a slow loading regime that was characterized by a steep inner activation barrier and a wide outer activation barrier, respectively. Furthermore, the authors applied the dissociation rate constant $\left(k_{2}^{0}\right)$ obtained from the force measurements to estimate the transition state energies. The energy between the transition states, $\mathrm{TS}_{1}$ and $\mathrm{TS}_{2}$, was shown to be $\Delta G_{12}=-k_{\mathrm{B}} T \ln \left(k_{2}^{0} / k_{1}^{0}\right)$. Their results show $\Delta G_{12}$ of the low-affinity and high-affinity complexes to be 2.7 and $5.5 k_{\mathrm{B}} T$, respectively. A lower limit for the activation energy of the inner barrier $\Delta G_{\mathrm{TS} 1}$ was the difference between the $\Delta G^{\circ}$ and $\Delta G_{12}$, where $\Delta G^{\circ}=-k_{\mathrm{B}} T \ln K_{\mathrm{d}}$. Taking the $K_{\mathrm{d}}$ values from Lollo et al. (1993), the corresponding $\Delta G^{\circ}$ for the low- and high-affinity interaction was calculated to be 9.2 and $14.8 k_{\mathrm{B}} T$, respectively.

\subsubsection{Granglioside $G_{M 1}$-cholera toxin B-oligomer (ctB) interaction}

Cai and Yang (2003) measured the binding strength and energy between cholera toxin B-pentamer (ctB) and its membrane receptor ganglioside GM1 by employing an AFM as an in situ molecular force probe (Fig. 9A). They obtained the AFM image in $20 \mathrm{mM} \mathrm{NaCl}$ of membrane-bound ctB on $\mathrm{G}_{\mathrm{M}^{-}}{ }^{-}$ incorporated egg PC bilayer in a surface plot with well-resolved individual pentamers (Fig. 9B). Moreover, they applied the basic principle of the reaction rate theory to determine the key parameters of the ligand-receptor binding potential from the experimental data. For the ctB- $\mathrm{G}_{\mathrm{M} 1}$ association, the binding potential energy $U$ as a function of the ligand-receptor distance has a well and a barrier (Fig. 9C). The depth of the well $\left(E_{\mathrm{b}}-E_{\mathrm{a}}\right)$ governs the rate of binding, and the height of the barrier $\left(E_{\mathrm{b}}\right)$ determines the difficulty to initiate the binding. The distribution function of the binding strength allowed them to deduce the microscopic spatial parameter. The potential had a well with a spatial span $(b-a)$ of about $2.5 \AA$ and a depth of at least six times the thermal energy $k_{\mathrm{B}} T$ at room temperature. Finally, they proved that the very short range nature of the binding potential $\left(4.7 k_{\mathrm{B}} T\right)$ leads to the specificity of the ctB$\mathrm{G}_{\mathrm{M} 1}$ coupling.

\subsubsection{Fibrinogen $\left(\alpha_{I I b} \beta_{3}\right)-R G D, A G D$ interaction}

Lee and Marchant (2003) used an AFM to study the interaction between a fibrinogen ligand and a platelet receptor $\alpha_{\text {IIb }} \beta_{3}$ under physiological conditions. Two linear peptide sequences in fibrinogen, RGD and HHLGGAKQAGDV, played central roles in the regulation of hemostasis and thrombosis by facilitating adhesion and aggregation of platelets. They synthesized the oligopeptide GSSSGaaa where aaa was RGDSPA or - HHLGGAKQAGDV to measure the interaction (i.e. debonding force) and grafted these oligopeptides on to the
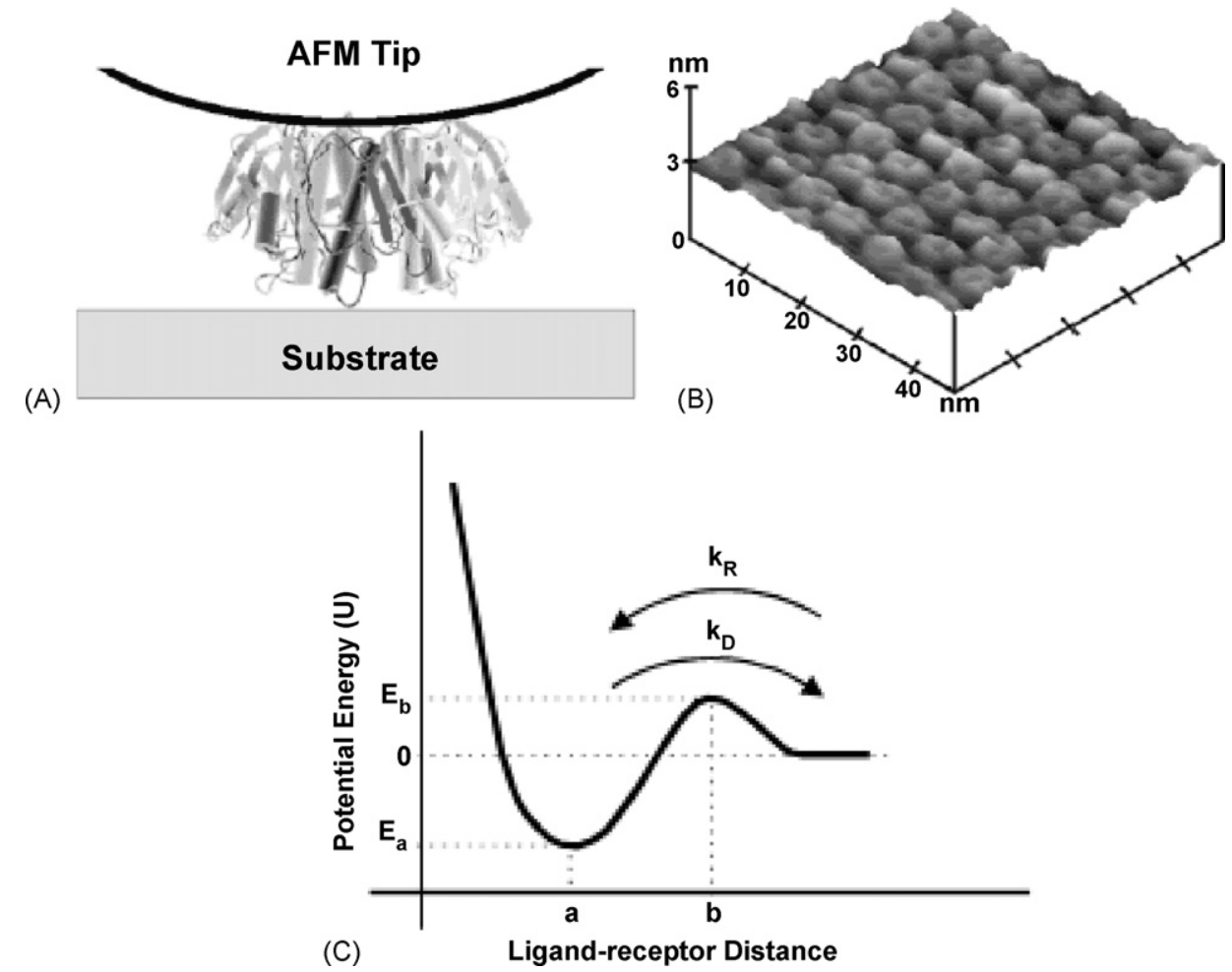

Fig. 9. (A) Model depicting actual molecular perspectives of the sandwich structure with tip-bound ctB between the tip and the substrate. (B) An AFM image obtained in $20 \mathrm{mM} \mathrm{NaCl}$ of membrane-bound ctB on a $\mathrm{G}_{\mathrm{M} 1}$-incorporated egg PC bilayer in a surface plot with well-resolved individual pentamers. (C) Illustration of the attractive potential responsible for the binding of ctB to its receptor $\mathrm{G}_{\mathrm{M} 1}$. The horizontal axis is the distance between the ctB and its receptor and the vertical axis is the potential energy $U$. The dissociation rate $k_{\mathrm{D}}$ and the recombination rate $k_{\mathrm{R}}$ are shown at the top of the potential barrier. Reprinted with permission from Cai and Yang (2003). Copyright 2003 American Chemical Society. 
(A)
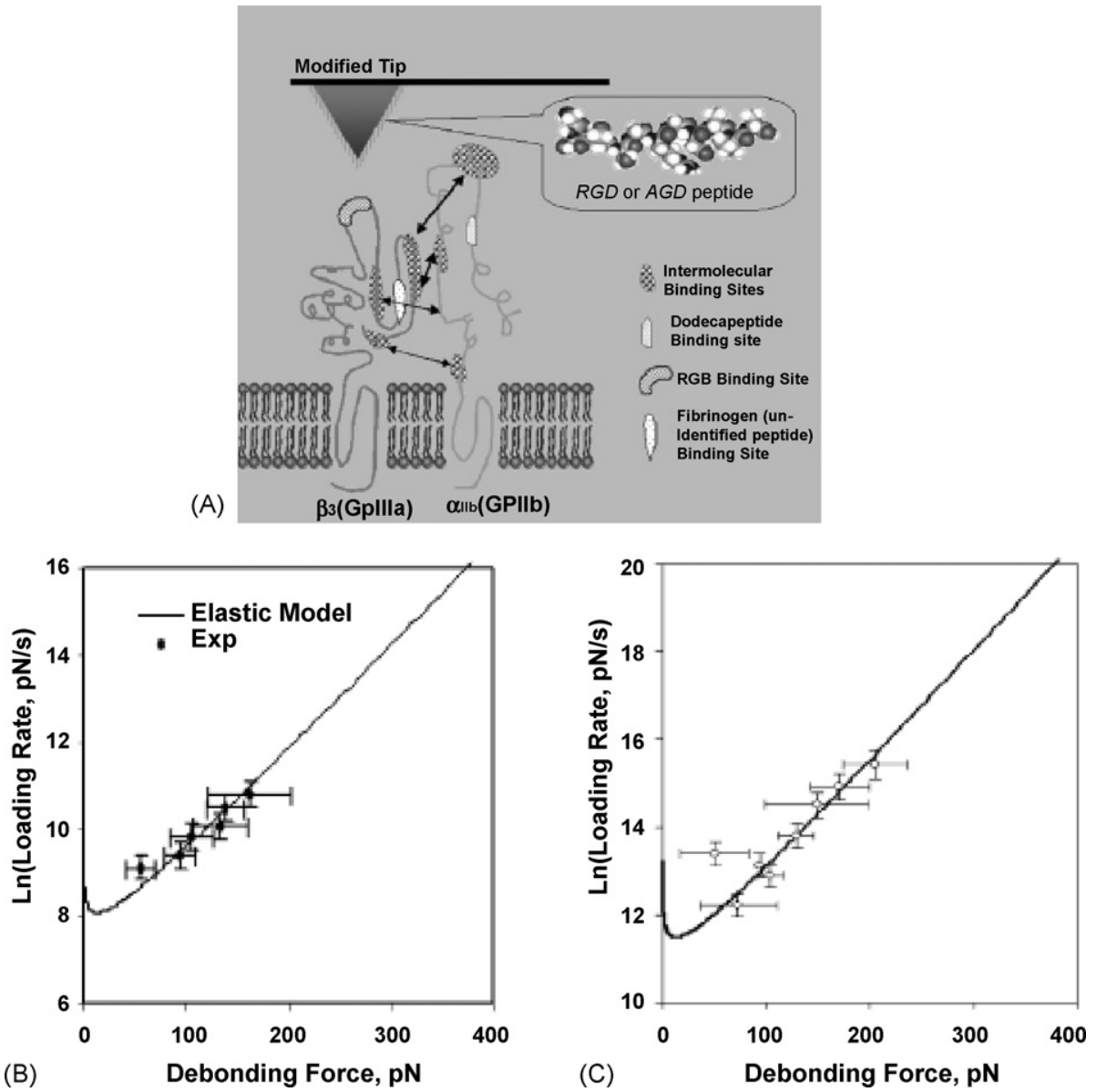

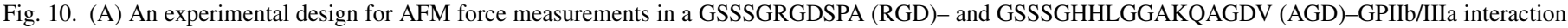

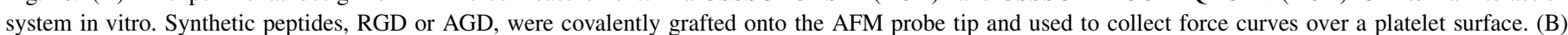

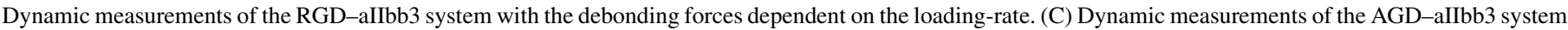
with the debonding forces dependent on the loading-rate. Reprinted with permission from Lee and Marchant (2003). Copyright 2003 Elsevier Science B.V.

surface of the AFM probe tip (Fig. 10A). The interaction force between a peptide-modified AFM probe tip and platelet surface was determined from a $\mathrm{pN}$ to a $\mathrm{nN}$ level using an AFM force measurement. They determined the $k_{\text {off }}(f)$ from the debonding force measurements in a range of a loading rate for RGD (and AGD) debonding events between 10 and $50 \mathrm{nN} / \mathrm{s}$. The results obtained showed that the zero kinetic off-rate, $k_{\text {off }}(0)$, for RGDSPA (Fig. 10B) was significantly smaller than that for HHLGGAKQAGDV (Fig. 10C), under the consideration of a flexible receptor surface. From their analysis, the single molecular binding energy $E_{\mathrm{b}}$; the $k_{\text {off }}(0)$; and the transition state $x_{\mathrm{b}}$; were extracted from the data, and determined to be $-2.64 \times 10^{-20} \mathrm{~J}, 1.53 \mathrm{~s}^{-1}$ and $1.03 \AA$ for the RGD- $\alpha_{\mathrm{II}} \beta_{3}$ system, and $-2.67 \times 10^{-20} \mathrm{~J}, 47.58 \mathrm{~s}^{-1}$ and $1.09 \AA$ for the HHLGGAKQAGDV $-\alpha_{\mathrm{IIb}} \beta_{3}$ system, respectively.

\section{Conclusions}

Since Hoh et al. (1993) first highlighted the ability of the AFM to directly measure discrete intermolecular forces of $10 \mathrm{pN}$ or less, the AFM has opened an innovative approach towards investigating directly the range and magnitude of the interaction forces between proteins and other molecules. It has also proved its value not only for resolving the topographical structure of protein samples, but also for its use as a tool to estimate affinity, rate constants, and structural data of binding pockets. In addition, the AFM can provide insight into the molecular dynamics of a protein-ligand recognition process by varying the loading rate of the force applied (force-spectroscopy).

Several techniques have been developed for measuring forces between biological structures, including mechanical springs made from glass fibers (Ishijima et al., 1996; Nicklas, 1983), vesicle-based force transducers (Evans et al., 1995), optical tweezers (Svoboda and Block, 1994) and surface-force apparatus (Israelachvili, 1992). Other approaches for investigating intermolecular forces include optical or diffraction methods to monitor the displacement of structures under a load resulting from osmotic (Parsegian et al., 1986) or hydrodynamic (Pierres et al., 1996) forces. These methods have sufficient sensitivity $(0.01-1 \mathrm{nN})$ to detect the intermolecular forces operative in protein-ligand binding but lack spatial resolution. The method of optical trapping (Kuo and Sheetz, 1993) is sufficiently sensitive but has a dynamic range that limits the breadth of the detectable force. A major advantage of the AFM over these other techniques is its spatial resolution and 
lateral resolution which is of paramount importance at $\mu \mathrm{m}$ and $\mathrm{nm}$ scales. However, an AFM has the disadvantage in that it is a surface technique for force measurement, implying that force is generated in only one direction. Especially in the case of rupture force measurements, this might not be the most energetically preferred method to separate complexes. Compared to other nanoscopic force measurement devices, such as optical, magnetic trapping or micropipettes, another disadvantage of the AFM is that the hydrodynamic damping is higher than in bulk liquid and thus the force sensitivity is intrinsically lower than those when measured using other techniques. Nevertheless, the AFM is a suitable technique to study a variety of different protein questions, whether they involve structural, molecular interactions or dynamic measurements. In addition, AFM has proven to be a valuable technique for proteomics with its own unique contributions towards our comprehension of the principles of protein folding and recognition.

\section{Acknowledgements}

The authors would like to thank Dr. Julie Lee and Dr. S.M. Hsu for their helpful suggestions and discussions.

\section{References}

Allen, S., Chen, X., Davies, J., Davies, M.C., Dawkes, A.C., Edwards, J.C., Roberts, C.J., Sefton, J., Tendler, S.J.B., Williams, P.M., 1997. Detection of antigen-antibody binding events with the atomic force microscope. Biochemistry $36,7457-7463$.

Allen, S., Davies, J., Dawkes, A.C., Davies, M.C., Edwards, J.C., Parker, M.C., Roberts, C.J., Sefton, J., Tendler, S.J.B., Williams, P.M., 1996. In situ observation of streptavidin-biotin binding on an immunoassay well surface using an atomic force microscope. FEBS Lett. 390, 161-164.

Bartels, F.W., Baumgarth, B., Anselmetti, D., Ros, R., Backer, A., 2003. Specific binding of the regulatory protein ExpG to promoter regions of the galactoglucan biosynthesis gene cluster of sinorhizobium meliloti-a combined molecular biology and force spectroscopy investigation. J. Struct. Biol. 143, 145-152.

Baumgartner, W., Hinterdorfer, P., Ness, W., Raab, A., Vestweber, D., Schindler, H., Drenckhahn, D., 2000. Cadherin interaction probed by atomic force microscopy. Proc. Natl. Acad. Sci. 97, 4005-4010.

Berry, M., Mcmaster, T.J., Corfield, A.P., Miles, M.J., 2001. Exploring the molecular adhesion of ocular mucins. Biomacromolecules 2, 498-503.

Bell, G.I., 1978. Models for the specific adhesion of cells to cells. Science 200, 618-627.

Binnig, G., Quate, C.F., Gerber, C., 1986. Atomic force microscopy. Phys. Rev. Lett. 56, 930-933.

Cai, X.E., Yang, J., 2003. The binding potential between the cholera toxin Boligomer and its receptor. Biochemistry 42, 4028-4034.

Chen, A., Moy, V.T., 2000. Cross-linking of cell surface receptors enhances cooperativity of molecular adhesion. Biophys. J. 78, 2814-2820.

Chen, C.H., Vesecky, S.M., Gewirth, A.A., 1992. In situ atomic force microscopy of underpotential deposition of silver on gold(l 111$)$. J. Am. Chem. Soc. 114, 451-458.

Chen, Y., Cai, J., Xu, Q., Chen, Z.W., 2004. Atomic force bio-analytics of polymerization and aggregation of phycoerythrin-conjugated immunoglobulin G molecules. Mol. Immunol. 41, 1247-1252.

Chilkoti, A., Boland, T., Ratner, B.D., Stayton, P.S., 1995. The relationship between ligand-binding thermodynamics and protein-ligand interaction forces measured by atomic force microscopy. Biophys. J. 69, 2125-2130.

Cleveland, J.P., Manne, S., Bocek, D., Hansma, P.K., 1993. A nondestructive method for determining the spring constant of cantilevers for scanning force microscopy. Rev. Sci. Instrum. 64, 403-405.
Dammer, U., Popescu, O., Wagner, P., Anselmetti, D., Güntherodt, H.J., Misevic, G.N., 1995. Binding strength between cell adhesion proteoglycans measured by atomic force microscopy. Science 267, 1173-1175.

Desmeules, P., Grandbois, M., Bondarenko, V.A., Yamazaki, A., Salesse, C., 2002. Measurement of membrane bBinding between recoverin, a calciummyristoyl switch protein, and lipid bilayers by AFM-based force spectroscopy. Biophys. J. 82, 3343-3350.

Dettmann, W., Grandbois, M., André, S., Benoit, M., Wehle, A.K., Kaltner, H., Gabius, H.J., Gaub, H.E., 2000. Differences in zero-force and force kinetics of ligand dissociation from $\beta$-galactoside-specific proteins (plant and animal lectins, immunoglobulin G) monitored by plasmon resonance and dynamic single molecule force microscopy. Arch. Biochem. Biophys. 383, $157-170$.

Evans, E., Leung, A., Simon, S., 2001. Chemically distinct transition states govern rapid dissociation of single L-selectin bonds under force. Proc. Natl. Acad. Sci. USA 98, 3784-3789.

Evans, E., Ritchie, K., 1997. Dynamic strength of molecular adhesion bonds. Biophys. J. 72, 1541-1555.

Evans, E., Ritchie, K., 1999. Strength of a weak bond connecting flexible polymer chains. Biophys. J. 76, 2439-2447.

Evans, E., Ritchie, K., Merkel, R., 1995. Sensitive force technique to probe molecular adhesion and structural linkages at biological interfaces. Biophys. J. 68, 2580-2587.

Fisher, T.E., Oberhauser, A.F., Carrion-Vazquez, M., Marszalek, P.E., Fernandez, J.M., 1999. The study of protein mechanics with the atomic force microscope. Trends Biochem. Sci. 24, 379-384.

Florin, E.L., Moy, V.T., Gaub, H.E., 1994. Adhesion forces between individual ligand-receptor pairs. Science 264, 415-417.

Fritz, J., Katopodis, A.G., Kolbinger, F., Anselmetti, D., 1998. Force-mediated kinetics of single P-selectin/ligand complexes observed by atomic force microscopy. Proc. Natl. Acad. Sci. USA 95, 12283-12288.

Grubmuller, H., Heymann, B., Tavan, P., 1996. Ligand binding: molecular mechanics calculation of the streptavidin-biotin rupture force. Science 271, 997-999.

Hansma, H.G., Oroudjev, E., Baudrey, S., Jaeger, L., 2003. TectoRNA and 'kissing-loop' RNA: atomic force microscopy of self-assembling RNA structures. J. Microsc. 212, 273-279.

Hinterdorfer, P., Baumgartner, W., Gruber, H.J., Schilcher, K., Schindler, H., 1996. Detection and locatization of individual antibody-antigen recognition events by atomic force microscopy. Proc. Natl. Acad. Sci. USA 93, $3477-$ 3481.

Hoh, J.H., Cleveland, J.P., Pratter, C.B., Revel, J.-P., Hansma, P.K., 1993. Quantized adhesion detected with the atomic force microscope. J. Am. Chem. Soc. 114, 4917-4918.

Hutter, J.L., Bechhoefer, J., 1994. Calibration of atomic force microscope tips. Rev. Sci. Instrum. 64, 1868-1873.

Ishijima, A., Kojima, H., Higuchi, H., Harada, Y., Funatsu, T., Yanagida, T., 1996. Multiple- and single-molecule analysis of the actomyosin motor by nanometer-picoNewton manipulation with a microneedle: unitary steps and forces. Biophys. J. 70, 383-400.

Israelachvili, J., 1992. Intermolecular and Surface Forces. Academic Press Limited, London.

Kada, G., Blayney, G., Jeyakumar, L.H., Kienberger, F., Pastushenko, V.P., Fleischer, S., Schindler, H., Lai, F.A., Hinterdorfer, P., 2001. Recognition force microscopy/spectroscopy of ion channels: applications to the skeletal $\mathrm{Ca}^{2+}$ release channel (RYR1). Ultramicroscopy 86, 129-137.

Kaur, J., Singh, K.V., Schmid, A.H., Varshney, G.C., Suri, C.R., Raje, M., 2004. Atomic force spectroscopy-based study of antibody pesticide interactions for characterization of immunosensor surface. Biosens. Bioelectron. 20, 284-293.

Kienberger, F., Kada, G., Gruber, H.J., Pastushenko, V., Riener, C., Trieb, M., Knaus, H.G., Schindler, H., Hinterdorfer, P., 2000. Rcognition force spectroscopy studies of the NTA-His6 bond. Single Molecules 1, 59-65.

Kienberger, F., Kada, G., Mueller, H., Hinterdorfer, P., 2005. Single molecule studies of antibody-antigen interaction strength versus intra-molecular antigen stability. J. Mol. Biol. 347, 597-606.

Kokkoli, E., Ochsenhirt, S.E., Tirrell, M., 2004. Collective and single-molecule interactions of $\alpha_{5} \beta_{1}$ integrins. Langmuir 20, 2397-2404. 
Kramers, H.A., 1940. Brownian motion in a field of force and the diffusion model of chemical reactions. Physia (Amsterdam) 7, 284.

Kuo, S., Sheetz, M., 1993. Force of single kinesin molecules measured with optical tweezers. Science 260, 232-234.

Kuznetsov, Y.G., Daijogo, S., Zhou, J., Semler, B.L., McPherson, A., 2005. Atomic force microscopy analysis of icosahedral virus RNA. J. Mol. Biol. $347,41-52$.

Lee, G.U., Kidwell, D.A., Colton, R.J., 1994. Sensing discrete streptavidinbiotin interactions with atomic force microscopy. Langmuir 10, 354-357.

Lee, I., Marchant, R.E., 2001. Force measurements on the molecular interactions between ligand (RGD) and human platelet $\alpha_{\text {IIB }} \beta_{3}$ receptor system. Surf. Sci. 491, 433-443.

Lee, I., Marchant, R.E., 2003. Molecular interaction studies of hemostasis: fibrinogen ligand-human receptor interactions. Ultramicroscopy $97,341-$ 352.

Lehenkari, P.P., Horton, M.A., 1999. Single integrin molecule adhesion forces in intact cells measured by atomic force microscopy. Biochem. Biophys. Res. Commun. 259, 645-650.

Li, H., Linke, W.A., Oberhauser, A.F., Carrion-Vazquez, M., Kerkviiet, J.G., Lu, H., Marszalek, P.E., Fernandez, J.M., 2002. Reverse engineering of the giant muscle protein titin. Nature 418, 998-1002.

Li, S., Palmer, A.F., 2004. Structure of small actin-containing liposomes probed by atomic force microscopy: effect of actin concentration and liposome size. Langmuir 20, 7917-7925.

Lin, S., Wang, Y.-M., Huang L.-S., Lin, C.-W., S.-M. Hsu, Lee, C.-K., in press Dynamic response of glucagons/anti-glucagon pairs to pulling velocity and $\mathrm{pH}$ studied by atomic force microscopy. Biosens. Bioelectron.

Lo, Y.S., Huefner, N.D., Chan, W.S., Stevens, F., Harris Jr., J.M., T.P.B., 1999. Specific interactions between biotin and avidin studied by atomic force microscopy using the poisson statistical analysis method. Langmuir 15, 1373-1382.

Lo, Y.S., Zhu Jr., Y.J., T.P.B., 2001. Loading-rate dependence of individual ligand-receptor bond-rupture forces studied by atomic force microscopy. Langmuir 17, 3741-3748.

Lollo, B.A., Chan, K.W., Hanson, E.M., Moy, V.T., Brian, A.A., 1993. Direct evidence for two affinity states for lymphocyte function associated antigen 1 on activated T cells. J. Biol. Chem. 268, 21693-21700.

Marshall, B.T., Long, M., Piper, J.W., Yago, T., Mcever, R.P., Zhu, C., 2003. Direct observation of catch bonds involving cell-adhesion molecules. Nature 423, 190-193.

Meadows, P.Y., Bemis, J.E., Walker, G.C., 2003. Single-molecule force spectroscopy of isolated and aggregated fibronectin proteins on negatively charged surfaces in aqueous liquids. Langmuir 19, 9566-9572.

Merkel, R., Nassoy, P., Leung, A., Ritchie, K., Evans, E., 1999. Energy landscapes of receptor-ligand bonds explored with dynamic force spectroscopy. Nature 397, 50-53.

Moy, V.T., Florin, E.L., Gaub, H.E., 1994. Intermolecular forces and energies between ligands and receptors. Science 264, 415-417.

Mueller, H., Butt, H.J., Bamberg, E., 1999. Force measurement on myelin basic protein adsorbed to mica and lipid bilayer surfaces done with the atomic force microscopy. Biophys. J. 76, 1072-1079.

Nakajima, H., Kunioka, Y., Nakano, K., Shimizu, K., 1997. Scanning force microscopy of the interaction events between a single molecule of heavy meromyosin and actin. Biochem. Biophys. Res. Commun. 234, $178-182$.

Nevo, R., Stroh, C., Kienberger, F., Kaftan, D., Brumfld, V., Elbaum, M., Reich, Z., Hinterdorfer, P., 2003. A molecular switch between alternative conformational states in the complex of Ran and importin $\beta 1$. Nat. Struct. Biol. 10 (7), 553-557.

Nicklas, R.B., 1983. Measurements of the force produced by the mitotic spindle in anaphase. J. Cell Biol. 97, 542-548.

Oberleithner, H., Schneider, S.W., Albermann, L., Hillebrand, U., Ludwig, T., Riethmuller, C., Shahin, V., Schafer, C., Schillers, H., 2003. Endothelial cell swelling by aldosterone. J. Membr. Biol. 196, 163-172.
Osada, T., Itoh, A., Ikai, A., 2003. Mapping of the receptor-associated protein (RAP) binding proteins on living fibroblast cells using an atomic force microscope. Ultramicroscopy 97, 353-357.

Paci, E., Caflisch, A., Plückthun, A., Karplus, M., 2001. Forces and energetics of hapten-antibody dissociation: a based molecular dynamics simulation study. J. Mol. Biol. 314, 589-605.

Parsegian, V.A., Rand, R.P., Fuller, N.L., Rau, D.C., 1986. Osmotic stress for the direct measurement of intermolecular forces. Meth. Enzymol. 127, 400-416.

Pierres, A., Benoliel, A.M., Bongrand, P., van der Merwe, P.A., 1996. Determination of the lifetime and force dependence of interactions of single bonds between surface-attached CD2 and CD48 adhesion molecules. Proc. Natl. Acad. Sci. USA 93, 15114-15118.

Popescu, O., Checiu, I., Ghergel, P., Simon, Z., Misevic, G.N., 2003. Quantitative and qualitative approach of glycan-glycan interactions in marine sponges. Biochimie 85, 181-188.

Reddy, C.V.G., Malinowska, K., Menhart, N., Wang, R., 2004. Identification of TrkA on living PC12 cells by atomic force microscopy. Biochim. Biophys. Acta 1667, 15-25.

Ros, R., Schwesinger, F., Anselmetti, D., Kubon, M., Schäfer, R., Plückthun, A., Tiefenauer, L., 1998. Antigen binding forces of individually addressed single-chain Fv antibody molecules. Proc. Natl. Acad. Sci. 95, 7402-7405.

Schafer, C., Shahin, V., Albermann, L., Hug, M.J., Reinhardt, J., Schillers, H., Schneider, S.W., Oberleithner, H., 2002. Aldosterone signaling pathway across the nuclear envelope. Proc. Natl. Acad. Sci. USA 99, 7154-7159.

Schwesinger, F., Ros, R., Strunz, T., Anselmetti, D., Guntherodt, H.J., Honegger, A., 2000. Unbinding forces of single antibody-antigen complexes correlate with their rates. Proc. Natl. Acad. Sci. USA 97, 9972-9977.

Senden, T.J., Ducker, W.A., 1994. Experimental determination of spring constants in atomic force microscopy. Langmuir 10, 1003-1004.

Sitko, J.C., Mateescu, E.M., Hansma, H.G., 2003. Sequence-dependent DNA condensation and the electrostatic zipper. Biophys. J. 84, 419-431.

Sletmoen, M., Skjak-Bræk, G., Stokke, B.T., 2004. Single-molecular pair unbinding studies of mannutonan C-5 epimerase AlgE4 and its polymer substrate. Biomarcomolecules 5, 1288-1295.

Stevens, M.M., Allen, S., Davies, M.C., Robert, C.J., Schacht, E., Tendler, S.J.B., VanSteenkiste, S., Williams, P.M., 2002. The development, characterization, and demonstration of a versatile immobilization strategy for biomolecular force measurements. Langmuir 18, 6659-6665.

Stuart, J.K., Hlady, V., 1995. Effects of discrete protein-surface interactions in scanning force microscopy adhesion force measurements. Langmuir 11, 1368-1374.

Svoboda, K., Block, S.M., 1994. Biological applications of optical forces. Annu. Rev. Biophys. Biomol. Struct. 23, 247-285.

Tees, D.F., Waugh, R.E., Hammer, D.A., 2001. A microcantilever device to assess the effect of force on the lifetime of selectin-carbohydrate bonds. Biophys. J. 80, 668-682.

Vickier, A., Gervasoni, P., Zaugg, F., Ziegler, U., Lindler, P., Groscurth, P., 1998. Atomic force microscopy detects changes in the interaction forces between GroEl and substrate proteins. Biophys. J. 74, 3256-3263.

Willemsen, O.H., Snel, M.M., van der Werfs, K.O., de Grooth, B.G., Greve, J., Hinterdorfer, P., Gruber, H.J., Schindler, H., van Kooyk, Y., Figdor, C.G., 1998. Simultaneous height and adhesion imaging of antibody-antigen interactions by atomic force microscopy. Biophys. J. 75, 2220-2228.

Wong, S.S., Joselevich, E., Woolley, A.T., Cheung, C.L., Lieber, C.M., 1998. Covalently functionalized nanotubes as nanometresized probes in chemistry and biology. Nature 394, 52-55.

Yip, C.M., Yip, C.C., Ward, M.D., 1998. Direct force measurements of insulin monomer-monomer interactions. Biochemistry 37, 5439-5449.

Yuan, C., Chen, A., Kolb, P., Moy, V.T., 2000. Energy landscape of streptavidinbiotin complexes measured by atomic force microscopy. Biochemistry 39 , 10219-10223.

Zhang, X., Wojcikiewicz, E., Moy, T.V.T., 2002. Force spectroscopy of the leukocyte function-associated antigen-1/intercellular adhesion molecule-1 interaction. Biophys. J. 83, 2270-2279. 